Delft University of Technology

\title{
Conceptual design of a passively safe thorium breeder pebble bed reactor
}

Wols, FJ; Kloosterman, JL; Lathouwers, D; van der Hagen, THJJ

DOI

10.1016/j.anucene.2014.09.012

Publication date

2015

Document Version

Final published version

Published in

Annals of Nuclear Energy

\section{Citation (APA)}

Wols, FJ., Kloosterman, JL., Lathouwers, D., \& van der Hagen, THJJ. (2015). Conceptual design of a passively safe thorium breeder pebble bed reactor. Annals of Nuclear Energy, 75, 542-558.

https://doi.org/10.1016/j.anucene.2014.09.012

\section{Important note}

To cite this publication, please use the final published version (if applicable).

Please check the document version above.

\section{Copyright}

Other than for strictly personal use, it is not permitted to download, forward or distribute the text or part of it, without the consent of the author(s) and/or copyright holder(s), unless the work is under an open content license such as Creative Commons.

\section{Takedown policy}

Please contact us and provide details if you believe this document breaches copyrights.

We will remove access to the work immediately and investigate your claim. 
Delft University of Technology

\section{Conceptual design of a passively safe thorium breeder pebble bed reactor}

Wols, Frank; Kloosterman, Jan-Leen; Lathouwers, Danny; van der Hagen, Tim

DOI

10.1016/j.anucene.2014.09.012

Publication date

2015

Document Version

Final published version

Published in

Annals of Nuclear Energy

\section{Citation (APA)}

Wols, FJ., Kloosterman, JL., Lathouwers, D., \& van der Hagen, THJJ. (2015). Conceptual design of a passively safe thorium breeder pebble bed reactor. Annals of Nuclear Energy, 75, 542-558.

https://doi.org/10.1016/j.anucene.2014.09.012

\section{Important note}

To cite this publication, please use the final published version (if applicable).

Please check the document version above.

\section{Copyright}

Other than for strictly personal use, it is not permitted to download, forward or distribute the text or part of it, without the consent of the author(s) and/or copyright holder(s), unless the work is under an open content license such as Creative Commons.

\section{Takedown policy}

Please contact us and provide details if you believe this document breaches copyrights.

We will remove access to the work immediately and investigate your claim. 
Green Open Access added to TU Delft Institutional Repository 'You share, we take care!' - Taverne project

\section{https://www.openaccess.nl/en/you-share-we-take-care}

Otherwise as indicated in the copyright section: the publisher is the copyright holder of this work and the author uses the Dutch legislation to make this work public. 


\title{
Conceptual design of a passively safe thorium breeder Pebble Bed Reactor
}

\author{
F.J. Wols*, J.L. Kloosterman, D. Lathouwers, T.H.J.J. van der Hagen \\ Delft University of Technology, Department of Radiation Science and Technology, Mekelweg 15, 2629 JB Delft, The Netherlands
}

\section{A R T I C L E I N F O}

\section{Article history:}

Received 21 January 2014

Received in revised form 4 September 2014

Accepted 6 September 2014

Available online 20 September 2014

\section{Keywords:}

Pebble Bed Reactor

Thorium

Breeding

Passive safety

Transients

\begin{abstract}
A B S T R A C T
More sustainable nuclear power generation might be achieved by combining the passive safety and high temperature applications of the Pebble Bed Reactor (PBR) design with the resource availability and favourable waste characteristics of the thorium fuel cycle. It has already been known that breeding can be achieved with the thorium fuel cycle inside a Pebble Bed Reactor if reprocessing is performed. This is also demonstrated in this work for a cylindrical core with a central driver zone, with $3 \mathrm{~g}$ heavy metal pebbles for enhanced fission, surrounded by a breeder zone containing $30 \mathrm{~g}$ thorium pebbles, for enhanced conversion.

The main question of the present work is whether it is also possible to combine passive safety and breeding, within a practical operating regime, inside a thorium Pebble Bed Reactor. Therefore, the influence of several fuel design, core design and operational parameters upon the conversion ratio and passive safety is evaluated. A Depressurized Loss of Forced Cooling (DLOFC) is considered the worst safety scenario that can occur within a PBR. So, the response to a DLOFC with and without scram is evaluated for several breeder PBR designs using a coupled DALTON/THERMIX code scheme. With scram it is purely a heat transfer problem (THERMIX) demonstrating the decay heat removal capability of the design. In case control rods cannot be inserted, the temperature feedback of the core should also be able to counterbalance the reactivity insertion by the decaying xenon without fuel temperatures exceeding $1600{ }^{\circ} \mathrm{C}$.

Results show that high conversion ratios $(\mathrm{CR}>0.96)$ and passive safety can be combined in a thorium PBR within a practical operating regime, which means a thermal power of $100 \mathrm{MW}$ or higher, 1000 days total residence time of the breeder pebbles and fuel pebble handling times longer than $14.5 \mathrm{~s}$, like in the HTR-PM. With an increased U-233 content of the fresh driver pebbles $(18$ w\%), breeding $(C R=1.0135)$ can already be achieved for a $220 \mathrm{~cm}$ core and $80 \mathrm{~cm}$ driver zone radius. While the decay heat removal is sufficient in this design, the temperature feedback of the undermoderated driver pebbles is too weak to compensate the reactivity insertion due to the xenon decay during a DLOFC without scram. With a lower U-233 content per driver pebble $(10 \mathrm{w} \%)$ it was found possible to combine breeding $(C R=1.0036)$ and passive safety for a $300 \mathrm{~cm}$ core and $100 \mathrm{~cm}$ driver zone radius, but this does require more than a doubling of the pebble handling speed and a high reprocessing rate of the fuel pebbles. The maximum fuel temperature during a DLOFC without scram was simulated to be $1481^{\circ} \mathrm{C}$ for this design, still quite a bit below the TRISO failure temperature. The maximum reactivity insertion due to an ingress of water vapour is also limited with a value of $+1497 \mathrm{pcm}$.
\end{abstract}

(ㄷ) 2014 Elsevier Ltd. All rights reserved.

\section{Introduction}

For future energy supply the combination of the inherent safety and high temperature applications of the Pebble Bed Reactor (PBR) design and the usage of thorium as a nuclear fuel is a promising option. Thorium is three to four times more abundant in the earth's crust than uranium, the use of thorium can reduce the radiotoxicity

\footnotetext{
* Corresponding author. Tel.: +31 152784041.

E-mail address: f.j.wols@tudelft.nl (F.J. Wols).
}

and the required storage time of nuclear waste. Furthermore, the $\mathrm{Th} / \mathrm{U}-233$ fuel cycle has favourable nuclear properties for use in thermal breeder reactors, compared to the U-238/Pu cycle (Lung and Gremm, 1998; IAEA, 2005). Teuchert (1986) already described the concept of a breeder thorium PBR. However, the design by Teuchert has a core radius of almost $6 \mathrm{~m}$, which makes it very difficult to achieve emergency cooling by passive means only.

Combining breeding, passive safety and high temperature applications could result in a state-of-the art reactor design, capable of fulfilling the demands on nuclear power generation in the 
21-st century. The aim of the present work is to investigate if both passive safety and breeding can be achieved, within a practical operating regime, within a thorium Pebble Bed Reactor.

An underlying assumption of the present work is that the U-233 content in the discharged pebbles can be reprocessed at a sufficient rate. The required reprocessing process itself is not a topic of the present work. Not so long ago, this reprocessing assumption might have been rather unrealistic due to the difficulties with mechanical separation methods for coated particle fuels (Lung, 1997), but Fütterer et al. (2010) recently made very promising progress in fragmenting coated particle fuels. Using high voltage discharges inside a water vessel, the contents of the fuel kernels can be separated with little energy consumption.

Neutronic studies of the fuel design (Wols et al., 2012) and the equilibrium core design (Wols et al., 2014a; Wols et al., 2014b) have been performed in previous work by the authors. The twozone cylindrical core consisted of a central driver zone surrounded by a breeder zone and the reflector and other structural components. The breeder pebbles have a $30 \mathrm{~g}$ heavy metal (HM) loading to obtain a relatively hard neutron spectrum, while still representing a conservative estimate from a fuel manufacturing perspective (Teuchert, 1986). This enhances neutron capture in Th-232, which subsequently decays into Pa-233 and into the fissile U-233. For the driver pebbles, a lower heavy metal loading is used to soften the neutron spectrum in order to enhance fission and reduce resonance absorption in the central driver zone. The fuel inside the driver pebbles consists of $U-233$ for $10 \mathrm{w} \%$. Each driver pebble makes several passes through the driver zone, while the residence time of the driver pebbles is adjusted to obtain a critical core configuration. In this work, an important addition is made to the original calculation scheme (Wols et al., 2014a) by including the spectral influence of surrounding zones (driver, breeder and reflector) into the fuel depletion calculations. This was found to have a significant impact on the conversion ratio. With this improved calculation scheme, it will be investigated for which fuel, core and operational parameters breeding might be achieved within a safe and practical operating regime. This practical operating regime is characterized by a thermal power of $100 \mathrm{MW}$ or higher for economical reasons, 1000 days total residence time of the breeder pebbles to limit the length of the running-in phase and a fuel pebble handling time longer than $14.5 \mathrm{~s}$, like in the High Temperature Reactor-Pebblebed Module (HTR-PM), to prevent engineering issues with the fuel handling system.

One of the key safety aspects of a thorium breeder core design is the reactor behaviour during a Depressurized Loss of Forced Cooling (DLOFC) transient. Due to the depressurization, conduction and radiation become the main heat transfer mechanisms for decay heat removal, while the contribution from (natural) convection is almost negligible. Due to the very limited heat transfer from the fuel to the surroundings the fuel will initially heat up significantly until the decay power equals the amount of heat transferred to the Reactor Heat Removal System (RHRS), located on the outer side of an airgap surrounding the reactor pressure vessel (Zheng et al., 2009). The maximum fuel temperature should remain below $1600^{\circ} \mathrm{C}$ to ensure all the radioactive fission products are retained within the fuel's tristructural-isotropic (TRISO) coating layers (Schenk et al., 1990).

Both the DLOFC with scram, which is solely a heat transfer problem, and without scram, involving fully coupled neutronics and thermal hydraulics, are investigated in this work. For the different breeder designs, it has to be demonstrated if the maximum fuel temperature can remain below the TRISO limit temperature of $1600{ }^{\circ} \mathrm{C}$ purely by passive means or not. So, also in the worst case scenario where control rods will not drop automatically for whatever reason. During the transient, an initial build-up of the concentration of Xe-135, a strong neutron absorber, is followed by a strong decrease, leading to a significant reactivity insertion into the core. Thus, besides the decay heat removal capacity, also the core's response to recriticality due to the reduced xenon concentration must ensure fuel temperatures below $1600{ }^{\circ} \mathrm{C}$.

In thorium PBRs, an additional reactivity insertion may originate from the decay of Pa-233 into U-233. However, this only becomes a significant effect in the very long run, as the half-life of Pa-233 is nearly 27 days, as compared to $9.14 \mathrm{~h}$ for Xe-135. So this effect has not been considered in the transients in the present work.

To perform the analysis of the transient behaviour of the thorium PBR, a coupled code scheme involving the SCALE6 code package (ORNL, 2009) for cross section generation, the DALTON neutron diffusion solver (Boer et al., 2010b) and the THERMIX thermal hydraulics code (Struth, 1995) for Pebble Bed Reactors, is used. The conversion ratio calculation scheme of the thorium PBR core configurations is discussed in Section 2. The coupled code scheme and the modelling approach for the transients will be introduced in Section 3. The conversion ratio is investigated for different core, fuel and operational parameters in Section 4, as well as the response of the relevant core designs to the DLOFC transients with and without scram. Based on these results, the possible design choices for a passively safe and/or breeder thorium PBR within a practical operating regime are discussed in Section 5, also with regard to the maximum possible reactivity increase due to water ingress. Finally conclusions will be drawn.

\section{Equilibrium core calculation of a thorium PBR core}

In previous work by Wols et al. (2014a), the neutronic design of a thorium breeder PBR was investigated for a cylindrical core consisting of an outer breeder zone and a central driver zone. Fig. 1 gives a schematic view of the reactor geometry used for the neutronic studies. Inside the side reflector there are porous regions to model the presence of helium in control rod channels and

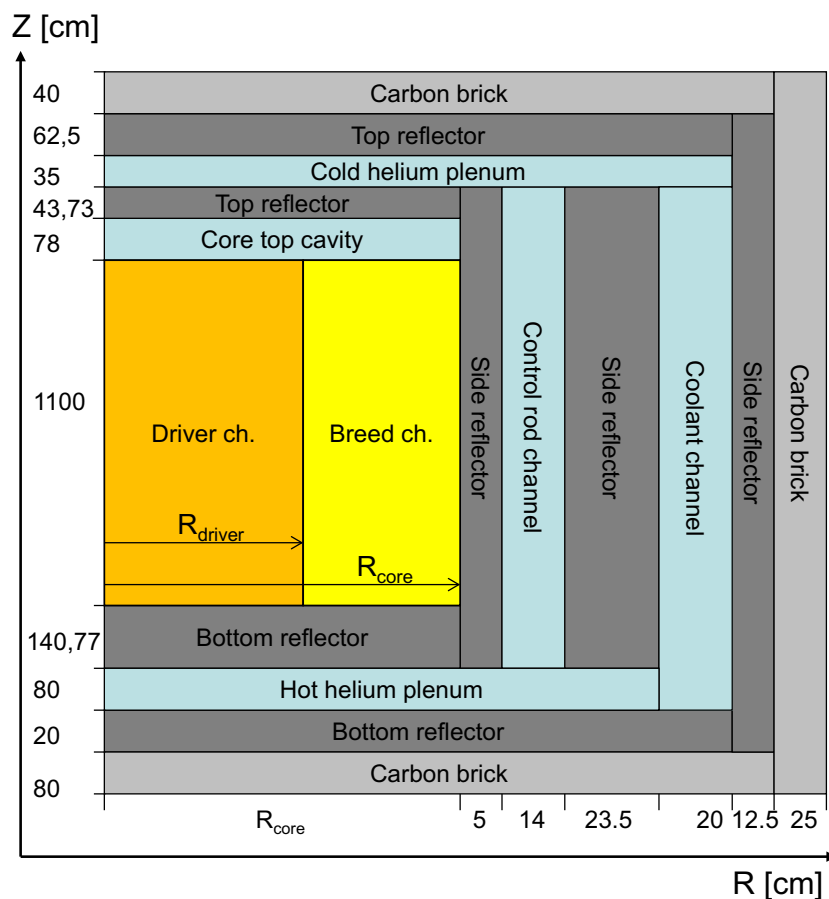

Fig. 1. Schematic view of the thorium PBR geometry used for the neutronics calculations, consisting of a cylindrical core with driver and breeder zone, surrounded by different graphite, helium or carbon brick layers. Dimensions are based on numbers given by Zheng and Shi (2008). 
coolant channels. To improve the convergence and accuracy of the neutron diffusion calculation the use of neutronically thin media is avoided in the calculations by homogenizing pure helium regions, like the top plenum, with adjacent graphite regions. For pure graphite reflector material a density of $1.76 \mathrm{~g} / \mathrm{cm}^{3}$ is used and $1.55 \mathrm{~g} / \mathrm{cm}^{3}$ for the carbon brick. Within the core region, a $10 \mathrm{~cm}$ grid size is used in the radial direction and $50 \mathrm{~cm}$ in axial direction during the diffusion calculations in the present work. For the surrounding reflector regions 9 additional cells are used in radial direction and 15 cells in axial direction.

Pebbles with $30 \mathrm{~g}$ thorium (in the form of $\mathrm{ThO}_{2}$ ) are inserted in the breeder zone (Wols et al., 2012; Wols et al., 2014a). Driver pebbles with 10 w\% (or more) U-233 and a much lower heavy metal loading, for improved moderation, are inserted into the driver zone. Besides the U-233, the driver pebble fuel kernels mainly consist of thorium with traces of the other uranium isotopes, according to their ratio's in the combined outflow of the driver and breeder zone. An overview of other pebble parameters (Wols et al., 2012; Ilas et al., 2006) used throughout the previous and the current studies is shown in Table 1.

The equilibrium core calculation scheme uses the CSAS and XSDRN modules from the SCALE6 code package for neutron cross section generation, COUPLE and ORIGEN (also SCALE6) for fuel depletion, and the DALTON code to perform $2 \mathrm{D}(\mathrm{R}, \mathrm{Z})$ neutron diffusion calculations of the core. During the first iteration, an initial flux guess is used for the depletion calculations of the breeder and driver pebbles while they move downwards, in 11 steps of one metre, in the core. First, cross sections are generated for a fresh fuel pebble at the top position $(11 \mathrm{~m})$, followed by a depletion calculation using the time period taken by the pebble to descend one metre to obtain nuclide concentrations for the fuel at a height of $10 \mathrm{~m}$. This is repeated until the pebble reaches the bottom of the core. At the bottom of the core a pebble is either reinserted into the core or extracted for reprocessing. The flux used in the depletion calculation is volume-averaged in the radial direction for the breeder and driver zone, obtaining a single radial nuclide concentration for the breeder and the driver zone at each pebble passage and height. The use of multiple radial depletion zones for driver and breeder, would have added many different refueling possibilities to a core design problem already involving many variables in the present conceptual design stage. Furthermore, the use of a single radial depletion zone for driver and breeder only has a limited impact upon the conversion ratio and leads to conservative results in terms of maximum power density and fuel pebble handling speed. This is demonstrated in Section 5.5 by also analyzing the three most promising core designs of this work with an extended model with eight radial depletion zones.

Using the updated set of nuclide concentrations and cross sections obtained for the driver and breeder zone over the height of the core, the flux profile can be updated by DALTON. This sequence of fuel depletion calculations, for the different pebble passes and heights in the two channels, and a core calculation is repeated until convergence of the flux and $\mathrm{k}_{\text {eff }}$ is achieved. An outer-iterative loop

Table 1

Fuel pebble parameters used for thorium breeder PBR design studies.

\begin{tabular}{ll}
\hline Pebble packing fraction & 0.61 \\
Pebble radius & $3.0 \mathrm{~cm}$ \\
Fuel zone radius & $2.5 \mathrm{~cm}$ \\
Fuel kernel radius & $0.25 \mathrm{~mm}$ \\
Material & Thickness [mm] \\
\hline Porous Carbon buffer layer & 0.09 \\
Inner pyrocarbon layer & 0.04 \\
Silicon Carbide layer & 0.035 \\
Outer pyrocarbon layer & 0.035 \\
Fuel mass breeder pebbles & $30 \mathrm{~g} \mathrm{HM}$ \\
\hline
\end{tabular}

adjusts the residence time of the driver pebbles to obtain a critical core configuration, while the breeder pebble residence time remains fixed. A detailed description of the equilibrium core calculation scheme is given by Wols et al. (2014a).

One important modification was made to the original equilibrium core calculation scheme (Wols et al., 2014a) with respect to the neutron spectrum used in the fuel depletion calculation. The influence of the surrounding zones (driver, breeder and reflector) upon the fuel depletion in the driver or breeder zone is now also taken into account by using the spectra calculated during the previous core iteration by $1 \mathrm{D}$ radial slab calculations for the different core heights. As there is no direct way to include these spectra in SCALE6.0, they are introduced into COUPLE and ORIGEN by overwriting the MT $=1099$ card, which contains the neutron spectrum of the nuclides included in the AMPX-library. A schematic view of the updated cross section and depletion spectrum generation scheme is shown in Fig. 2.

The surrounding zones (driver, breeder or reflector) have a significant negative impact ( $12 \%$ for one specific case) on the conversion ratio in comparison with previous results which did not include this effect (Wols et al., 2014a). Especially in the breeder zone the conversion rate of thorium into U-233 was exaggerated due to the combination of the thermal flux normalization convention used by ORIGEN and the spectrum mismatch between the whole core DALTON-calculation and the fuel depletion spectra.

After the calculation scheme has converged, the code calculates the system's U-233 mass balance, being the feed rate of U-233 $\left(\dot{m}_{U 3, \text { in }}\right)$, minus the extraction rate of U-233 ( $\left.\dot{m}_{U 3, \text { out }}\right)$ and Pa-233 $\left(\dot{m}_{P a 3, \text { out }}\right)$. Core configurations with a negative overall mass balance of U-233 plus Pa-233 are considered being a breeder reactor, assuming the uranium contents of the driver and breeder pebbles extracted from the core are fully reprocessed. The composition of the driver fuel, or more specifically the ratio between the concentrations of the other uranium isotopes and U-233, is determined by their ratio in the combined outflow of the driver and the breeder zone.

The conversion ratio (CR) is defined by Duderstadt and Hamilton (1976) as the average rate of fissile atom production divided by the average rate of fissile atom consumption. For the results presented in this work, a more practical approximate definition is used for the conversion ratio, since the absorption rate in the fissile atoms is not tracked separately in the code scheme.

$C R \approx 1+\frac{\dot{m}_{U 3, \text { out }}+\dot{m}_{P a 3, \text { out }}-\dot{m}_{U 3, \text { in }}}{\dot{m}_{U, f i s s i o n}}$.

The absorption-to-fission ratio for thermal neutrons in U-233 is approximately 1.0876 (IAEA, 2005). So, dividing by the fission rate instead of the fissile consumption rate leads to a slight overprediction of conversion ratio's above one and a slight underprediction of conversion ratio's below one, while the definition is exact for a conversion ratio of 1 . The main interest from a core design perspective is to know whether the CR is above unity or not. In the latter case a value close to one would be desirable.

\section{Coupled DALTON/THERMIX code scheme}

A code scheme coupling neutronics and thermal hydraulics was used for the analysis of the DLOFC transients in this work. The SCALE6 code package is used for the generation of the neutron cross sections libraries, the in-house developed diffusion solver DALTON to describe the core neutronics, and the THERMIX code is used for the thermal hydraulics calculation. A similar geometrical model as used by Zheng et al. (2009) and Zheng and Shi (2008) for the HTR-PM was used to model the thermal hydraulics of the thorium breeder Pebble Bed Reactor within THERMIX. 


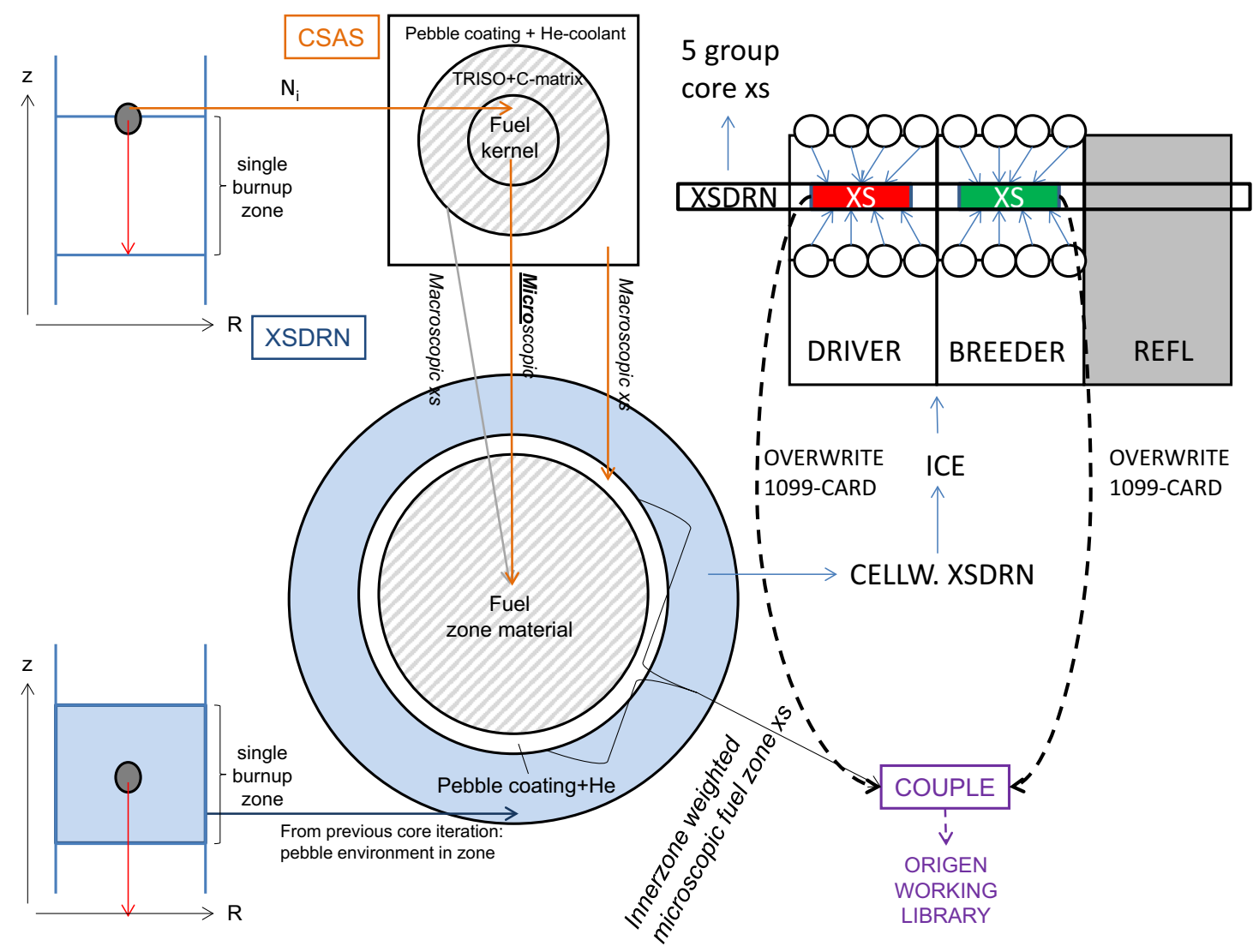

Fig. 2. Schematic view of the updated cross section generation method (the diagrams are not to scale).

\subsection{Temperature dependent cross section library}

The nuclide concentrations used in the determination of the temperature dependent cross section library are obtained using the equilibrium core calculation scheme previously developed by Wols et al. (2014a). A steady-state THERMIX run is included in each core iteration, so the influence of the temperature feedback upon the fuel depletion is properly included in the nuclide concentrations, though this hardly affects the breeding potential of the thorium PBR.

The first step to perform coupled neutronics and thermal hydraulics calculations is the generation of a cross section library for the Pebble Bed Reactor depending on fuel, moderator and reflector temperatures. Cross sections in these libraries are condensed to five energy groups using 1D XSDRN calculations over representative radial slabs of the core at eleven different core heights. These radial slabs consist of a driver zone, breeder zone and the various side reflector and surrounding regions depicted in Fig. 1. A buckling correction is applied to approximate axial leakage. Cross sections for the top and bottom reflectors are condensed using an axial XSDRN calculation. This process is performed in a similar way as in the equilibrium core calculation scheme (Wols et al., 2014a). In total 25 cross section libraries are generated for 5 different fuel and 5 different moderator + reflector temperatures, and merged into a single library. The temperatures used are $300 \mathrm{~K}$, $700 \mathrm{~K}, 1100 \mathrm{~K}, 1500 \mathrm{~K}$ and $1900 \mathrm{~K}$.

Using the ICE module of SCALE6, cross sections are mixed using interpolation on the basis of the actual fuel and moderator temperature (so using 4 interpolation coefficients) or the reflector temperature for each core region included in the neutron diffusion calculation. If a value above $1900 \mathrm{~K}$ occurs, the cross section at the limit temperature of $1900 \mathrm{~K}$ is used. Note that this value is above the TRISO safety limit temperature of $1600^{\circ} \mathrm{C}$.

When the steady-state temperature distribution of the core, $T(r, z)$, is known, uniform reactivity coefficients of the core can be calculated based on these temperature dependent libraries according to

$\alpha_{\text {uniform }}=\frac{\rho(T(r, z)+\Delta T)-\rho(T(r, z))}{\Delta T}$.

In the results section, the uniform reactivity coefficients are evaluated for a temperature increase, $\Delta T$, of $500^{\circ} \mathrm{C}$.

During the generation of the cross section library, the microscopic xenon cross sections are also generated for the different positions in the core, which can be used to include the xenon effect into the cross sections during a transient, as explained in Appendix A.

\subsection{Steady-state coupled calculation}

The following approach is used to acquire the steady-state temperature distribution of a Pebble Bed Reactor. An initial guess is used for the temperature (for instance a uniform $1100 \mathrm{~K}$ ) and a cross section set for this temperature is used by the neutron diffusion solver DALTON, which calculates $k_{\text {eff }}$, the flux and power density distribution over the core. The power density is handed over to THERMIX, which calculates the updated steady-state temperature profile, and from this a new cross section library is interpolated from the temperature dependent library. This process can be repeated until convergence is reached.

However, there is one complicating factor in the case of the two-zone thorium breeder PBR: Only the coolant flowing through 
the driver zone heats up significantly, but the largest fraction of the coolant flows through the breeder zone. So, the coolant flows extracted from the driver zone and the breeder zone have to be separated in the design. The hot helium flowing out of the driver zone is led to the steam generator (or turbine), while the slightly heated helium from the breeder zone is mixed with the cold helium $\left(250^{\circ} \mathrm{C}\right)$ to preheat it before entering the core. A schematic view of the helium coolant flow scheme inside the thorium breeder PBR is shown in Fig. 3. Note that in reality, as well as in the THERMIX model, there is just one helium flow from top to bottom through the whole core (so breeder and driver zone combined). For this reason, on average, a fraction of the flow is forced to move from the driver zone into the breeder zone due to the expansion of the hotter helium in the driver zone. Similar to the work of Zheng et al. (2009), the THERMIX model also includes bypass flows through the control rod channels, which account for roughly $1 \%$ of the total mass flow, and a leakage flow of $4 \%$ to $5 \%$ to simulate the flow through the gaps between the graphite components. These bypass flows are not shown in Fig. 3.

Such a complex scheme, i.e. the mixing of the preheated helium of the breeder zone outlet with the cold helium of $250{ }^{\circ} \mathrm{C}$ is not easy to model directly in the THERMIX code. Therefore, the inlet temperature of the THERMIX calculation, $T_{\text {in,core }}$, is adjusted. It is also difficult to model two outlet regions in THERMIX, so one for the driver and one for the breeder zone, because this is only possible if the user prescribes the mass flows at both the outflow regions, but in reality these are unknown a priori. So, the helium flows exiting the driver and breeder zones only remain separated up to a final single outflow zone where they are mixed. The advantage of this approach is that the helium mass flow is distributed over the driver zone and breeder zone in a natural way, since only the total core helium outflow is prescribed by the user. The mass flow and temperature of the breeder and driver zone outflow are read from the THERMIX output by choosing the appropriate cells, just before the streams are mixed in the final outflow zone.

With the outer system temperature, $T_{0}$, fixed at $250^{\circ} \mathrm{C}$, as with the regular HTR-PM, and the mass flows over the driver zone, $\dot{m}_{\text {driver }}$, and the breeder zone, $\dot{m}_{\text {breed }}$, obtained from the THERMIX output, the new inlet temperature $T_{\text {in,core }}$ follows from a simple balance

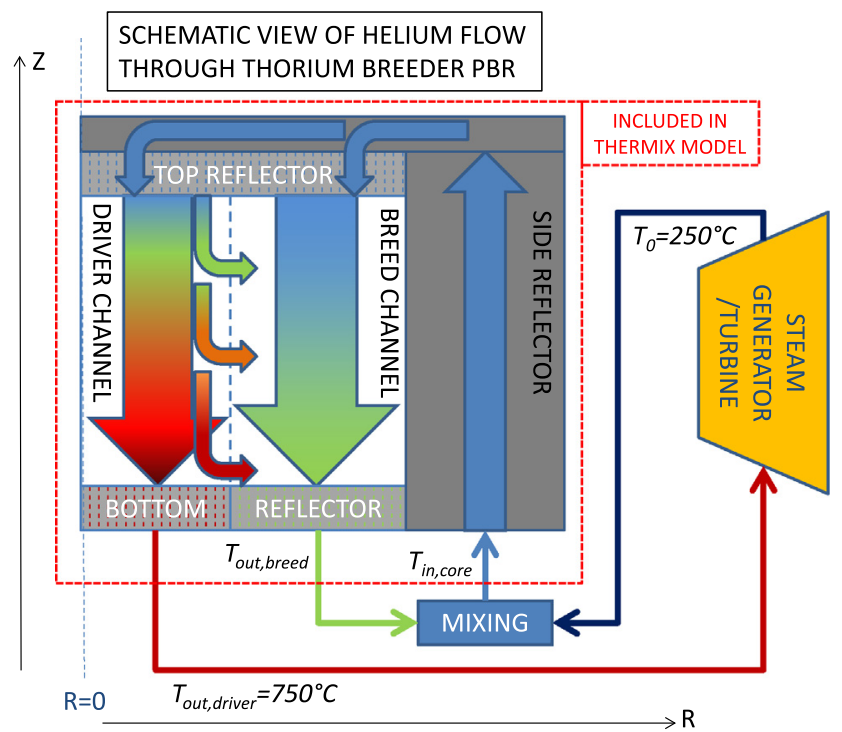

Fig. 3. Schematic view of the helium coolant flow scheme in the Thorium Breeder PBR.
$T_{\text {in, core }}=\frac{\dot{m}_{\text {driver }} T_{0}+\dot{m}_{\text {breed }} T_{\text {out }, \text { breed }}}{\dot{m}_{\text {total }}}$.

The total mass flow entering the core, $\dot{m}_{\text {total }}$, is the sum of $\dot{m}_{\text {breed }}$ and $\dot{m}_{\text {driver }}$. To ensure the (driver zone) outlet temperature remains at $750{ }^{\circ} \mathrm{C}$, the total mass flow of the coolant is increased (or decreased) iteratively in the numerical scheme.

A higher mass flow rate requires an increase of the pumping power which decreases the efficiency of the reactor. According to chapter 3 from Melese and Katz (1984) the pumping power increases linearly with the mass flow rate for a fixed pressure drop, e.g. if the mass flow rate increases proportionally to the pebble bed volume with increasing core diameter. But Melese and Katz (1984) also show that the pressure drop depends quadratically on the ratio between the mass flow rate and the flow surface area. So, any increase of the mass flow rate above proportional to the flow surface area increase, increases the required pumping power with the third power of the mass flow rate. An increase of the system pressure can help to reduce the required pumping power, as it varies inversely quadratically with the system pressure (Melese and Katz, 1984). However, the pumping power decrease comes at the price of an increase in construction costs of the reactor.

In the iterative steady-state scheme the core inlet temperature of THERMIX and the mass flow are adjusted in an iterative inner loop until convergence of the core inlet and outlet temperature is reached. The cross section and power profile are updated until convergence of $k_{\text {eff }}$ and the power profile in an outer iterative loop.

The method described above has also been implemented into the equilibrium core calculation scheme. However, in that case only a single volume-averaged temperature (and concentration) is used in the radial direction for the driver zone and a single volume-averaged temperature for the breeder zone. During the interpolation from the temperature dependent libraries, which will also be used during the coupled transient calculations, different temperatures are used for each radial grid zone. For the initial core configuration, this leads to a slight deviation from the original $k_{\text {eff }}$ of $1( \pm 0.0002)$ obtained with the core depletion scheme. To ensure the system is really in a steady-state at the start of the time-dependent calculation a (small) correction is applied twice (to eliminate second order effects) to the fission cross section, $\Sigma_{f}=\Sigma_{f} / k_{e f f}$, to force $k_{e f f}$ to be 1 .

\subsection{Transients}

During the DLOFC transients modelled in this work it is assumed that the reactor depressurizes instantaneously from 70 bar to 1 bar between 0 and $0.1 \mathrm{~s}$, which is a conservative estimate for the heat transfer (Zheng and Shi, 2008). Due to the depressurization, conduction and radiation are the dominant mechanisms to transfer the decay heat from the fuel to the reactor pressure vessel and the water cooling panel, while heat transfer due to natural convection is almost negligible. Due to the very small heat transfer from the fuel to the surroundings, the fuel will initially heat up until the decay power becomes smaller than the heat transfer to the Reactor Heat Removal System (RHRS), which consists of a water cooling panel kept at a constant temperature of $70^{\circ} \mathrm{C}$. The maximum fuel temperature should remain below $1600^{\circ} \mathrm{C}$ to ensure all the radioactive fission products remain contained within the fuel's TRISO coating layers.

\subsubsection{DLOFC with scram}

In a DLOFC with scram it is assumed that the fission power is reduced instantaneously due to the scram, so all the heat produced in the core originates from the decay heat. The decay heat profile of $\mathrm{U}-235$, according to the 23 exponents of the ANS decay heat standard from 1993 (American Nuclear Society, 1993), is used 
throughout the transients in the present work, as U-233 is not included in the ANS decay heat standard. Better decay heat data for U-233 would be desirable to improve the modelling of transients in U-233 fueled reactors.

Alternatively, the evolution of the decay heat fraction over time can roughly be described by the Way-Wigner equation (Kugeler et al., 2005), which is the standard method in older versions of the THERMIX code (Struth, 1995). The Way-Wigner equation describes the decay heat fraction as a function of time by

$\eta=0.0622\left(t^{-0.2}-\left(t_{0}+t\right)^{-0.2}\right)$,

where $t$ is time elapsed after the start of the transient in seconds and $t_{0}$ is the time the fuel has been irradiated at nominal power in seconds. The Way-Wigner approximation somewhat underpredicts the decay heat fraction during the initial stage of the transient, but gives a very similar decay heat fraction later on in the transient. Assuming the pebbles were irradiated for 365 days at the nominal operating power, the decay heat curves of the ANS-1993 standard and the Way-Wigner approximation are both plotted in Fig. 4 ranging from $1 \mathrm{~s}$ to $100 \mathrm{~h}$.

\subsubsection{DLOFC without scram}

Without scram, the power in the reactor will slowly decrease due to the negative temperature feedback as the fuel temperature increases after the DLOFC. During this period, the heat generated in the fuel is the sum of the actual fission power and the decay heat generated in the fuel. In the calculation scheme, the actual heat generated in the fuel is approximated by adding up the actual fission power $\mathrm{P}_{\text {fission }}$, calculated by DALTON, and the decay heat fraction at time $t$ after the start of the transient times the difference between the nominal operating power $\mathrm{P}_{0}$ and the actual fission power $\mathrm{P}_{\text {fission, }}$,

$P_{\text {total }}(t)=P_{\text {fission }}(t)+\eta(t)\left(P_{0}-P_{\text {fission }}(t)\right)$.

For a correct understanding of this definition, one should be aware that the steady-state fission power calculated by DALTON contains contributions from both the prompt fission power and a delayed heat release, which one refers to as the decay heat after the start of the transient.

Using the decay heat fraction starting from $t=0$ for all the decay heat generated may lead to some inaccuracy during the initial minutes of the transient, but the effect is negligible for the peak fuel temperatures, which occur after many hours in the transient. It does not matter that much anymore for the decay heat fraction $\eta(t)$ whether $\mathrm{t}$ is $10 \mathrm{~h}$ or $10 \mathrm{~h}$ and a few minutes.

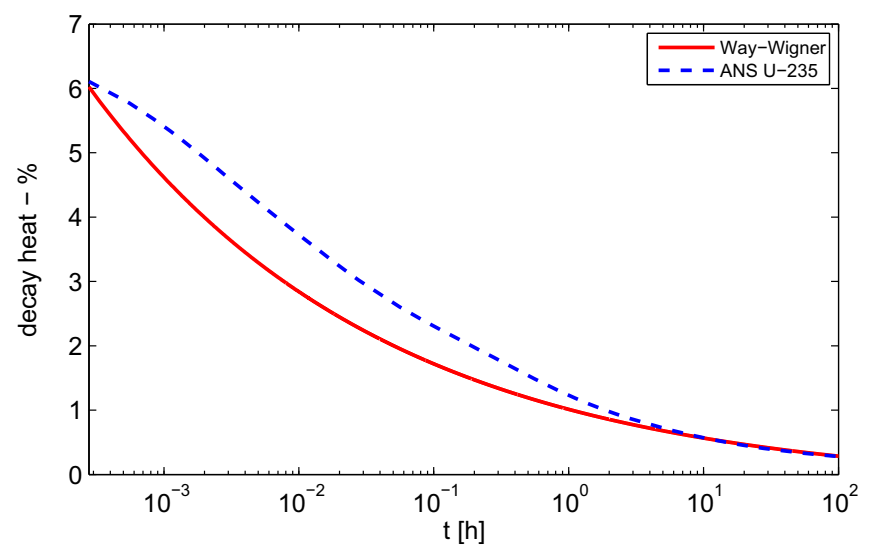

Fig. 4. Decay heat as a function of time using the Way-Wigner approximation (Kugeler et al., 2005) of Eq. (4) [ $t_{0}=365$ days $]$ and using the ANS decay heat standard for U-235 (American Nuclear Society, 1993).
During the first period of the transient the calculation is run in a fully coupled mode, so THERMIX frequently exchanges the updated fuel temperatures with SCALE and DALTON to update cross sections and the power profile. At the moment the ratio of the fission power over the decay heat power becomes smaller than 0.1 the calculation switches over to a loosely coupled mode and the time step size is increased. A threshold of 0.1 ensures no computational time is wasted, because the contribution of fission to the core temperature increase becomes marginal $\left(\approx 0.1^{\circ} \mathrm{C}\right)$ after reaching the threshold. In the loosely coupled mode THERMIX is run solely using the decay heat power obtained by the ANS-1993 Standard, DALTON is now run in static mode to calculate $k_{\text {eff }}$.

During the transient the xenon concentration, i.e. Xe-135, will initially increase to give a negative reactivity contribution and later on decrease and give a positive reactivity contribution. The method to include the xenon effect into the calculation scheme is explained in Appendix A. At a certain moment, the decrease of the xenon concentration results in re-criticality of the core. In the loosely coupled mode the time step size is reduced as $k_{\text {eff }}$ approaches one. When $k_{\text {eff }}$ becomes one the calculation switches to dynamic (so fully coupled) mode again and the fission power restarts at a value of $100 \mathrm{~W} .100 \mathrm{~W}$ is still a very small fraction of the total heat production, but also ensures no computation time is wasted for very small fission powers. DALTON and THERMIX exchange power and temperature profile every $20 \mathrm{~s}$, this is increased up to $80 \mathrm{~s}$ if the change in fission power becomes very small during a time step. A schematic view of the time-dependent DALTON/THERMIX coupling scheme is shown in Fig. 5.

\section{Core parameter studies}

Many parameters that influence the conversion ratio of a thorium PBR might be varied in the core design. The main parameters are the heavy metal loading of the driver and the breeder pebbles, the $\mathrm{U}-233$ weight fraction of the driver fuel, the radius of the core and the driver zone, the residence time of the breeder pebbles, reactor power and the number of passes a pebble makes through the driver and the breeder zone.

In view of the calculation time of a single equilibrium core simulation it is certainly not possible to study all possible parameter combinations. The number of options can be narrowed down significantly by taking into account practical constraints and by

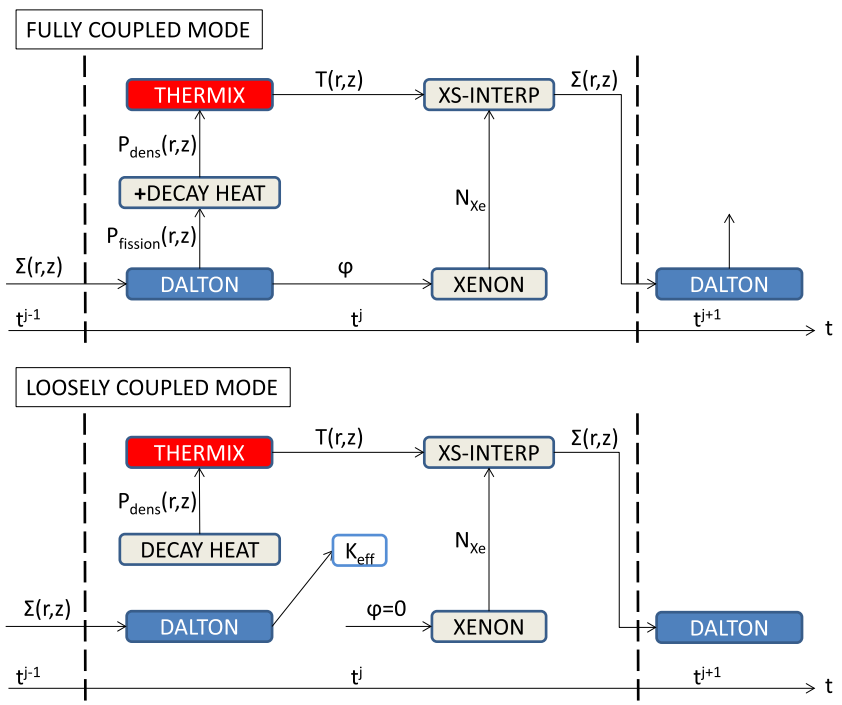

Fig. 5. Schematic view of the coupled DALTON/THERMIX code scheme during fully coupled and loosely coupled run. 
excluding parameter choices with a certain negative impact on safety, such as a very high reactor power. Furthermore, the conversion ratios obtained in previous work (Wols et al., 2014a; Wols et al., 2014b) did not include the spectral influence of the surrounding zones (driver, breeder, reflector), but many of the trends observed still provide a useful starting point in order to achieve a core configuration with a high conversion ratio. Finally, design variations are mostly investigated for one parameter at a time to limit the number of core calculations.

\subsection{U-233 weight fraction of driver fuel}

Ideally the combination of the U-233 weight fraction of the driver fuel and the heavy metal loading per driver pebble are chosen to ensure operation around the optimal moderator-to-fuel ratio of the core, so ensuring the highest fission over absorption ratio in the driver zone. A U-233 weight fraction of $12 \%$ is used for the driver fuel as a starting point. A lower weight fraction would result in difficulties reaching criticality with a small driver zone radius. A small driver zone ensures a high fraction of neutrons leak into the breeder zone which enhances conversion. A higher U-233 weight fraction of the driver fuel, with the same metal loading, may be desirable to reduce the pebble handling speed for the core and/or allow for a smaller driver zone radius, which could improve the conversion ratio. This option will be investigated later on. On the downside, a higher U-233 weight fraction may present problems in terms of passive safety, as reactivity coefficients become less negative and the reactivity increase due to water ingress becomes stronger as the core becomes undermoderated.

\subsection{Heavy metal loading}

Breeder pebbles are filled with $30 \mathrm{~g}$ thorium (Wols et al., 2012), a conservative estimate of the maximum possible loading from a fuel fabrication perspective (Teuchert, 1986). Each breeder pebble makes two passes through the core in the calculations in the present work. Adding more passes does not significantly improve the conversion ratio, but might put a very high demand on the fuel handling system.

For the driver pebbles, a $3 \mathrm{~g}$ HM loading is used as a starting point. This is bit above the optimal moderator-to-fuel ratio (Wols et al., 2012) if a U-233 weight fraction of $12 \%$ is used, but low enough to ensure that water ingress cannot lead to a large reactivity insertion (see Section 5.3). The reactivity coefficients are also more negative for lower driver pebble heavy metal loadings (Wols et al., 2014b) improving the safety of the core during a DLOFC without scram.

\subsection{Reactor power}

For the thermal power of the reactor a minimum constraint of $100 \mathrm{MW}$ is used. Lower values are undesirable from an economical perspective and it will also take a very long time to achieve the equilibrium core configuration as the irradiation of the breeder pebbles becomes very slow. A maximum of $250 \mathrm{MW}$ is used for the thermal power, similar to the HTR-PM. As the core radius of a high-conversion thorium PBR is generally much larger than for the HTR-PM, decay heat removal is probably insufficient for a higher power, so fuel temperatures are likely to exceed $1600{ }^{\circ} \mathrm{C}$ in that case.

The influence of the reactor power on the conversion ratio, calculated by Eq. (1), was determined for a typical thorium PBR of $300 \mathrm{~cm}$ radius with a $100 \mathrm{~cm}$ driver zone radius. A breeder pebble residence time of 2000 days was used, which is rather high from a practical perspective, but it ensures sufficient irradiation of the breeder pebbles. Shorter and more practical residence times of the breeder pebbles will also be investigated later on.
The results in Table 2 indicate that the conversion ratio does not vary a lot with reactor power. For $100 \mathrm{MWth}, 150 \mathrm{MWth}$ and 200 MWth the CR is almost equal, and close to 1. At a power of 250 MWth it increases a bit due to the fact that a larger fraction of the power is produced in the breeder zone and this enhances conversion more than the decrease caused by additional neutron capture due to the higher Pa-233 concentrations. This also indicates that the optimal breeder pebble residence time for this configuration would even be larger than 2000 days. A breeder pebble residence time of 5000 days ( $P=100 \mathrm{MWth}$ ) would increase the conversion ratio up to 1.0011 , but this is impractical considering the typical lifetime of a reactor.

As could be expected, the driver pebble recycling speed and pebble reprocessing rate also increase with increasing reactor power. The maximum fuel temperatures during a DLOFC with scram, shown in Table 2, indicate that decay heat removal is a problem for reactor powers of $200 \mathrm{MWth}$ and larger, since fuel temperatures exceed the TRISO limit temperature of $1600{ }^{\circ} \mathrm{C}$. From a decay heat removal perspective it would be wise to limit the core power to $150 \mathrm{MWth}$ for a core configuration with a $300 \mathrm{~cm}$ core radius.

The maximum fuel temperature during a DLOFC with and without scram is shown in Fig. 6 for reactor powers of 100 MWth and

\section{Table 2}

Overview of conversion ratio, fuel management and safety parameters for different reactor powers $\left(T_{\text {res, tot }}^{\text {breed }}=2000[\mathrm{~d}], \epsilon_{\text {driver }}^{U-233, \text { in }}=12[\mathrm{w} \%], R_{\text {core }}=300[\mathrm{~cm}], R_{\text {driver }}\right.$ $=100[\mathrm{~cm}], 15$ driver pebble passes and 2 breeder pebble passes).

\begin{tabular}{lllll}
\hline Case & I & II & III & IV \\
Thermal power [MW] & 100 & 150 & 200 & 250 \\
\hline Conversion ratio & 0.9913 & 0.9915 & 0.9914 & 0.9932 \\
$T_{\text {rriver tot }}^{\text {drive }}[\mathrm{d}]$ & 323 & 229 & 183 & 157 \\
$P_{\text {density }}^{\text {max }}\left[\mathrm{MW} / \mathrm{m}^{3}\right]$ & 6.2 & 8.6 & 10.6 & 12.4 \\
Pebble handling time $[\mathrm{s}]$ & 8.5 & 6.3 & 5.1 & 4.5 \\
Reprocessing rate $[\mathrm{p} / \mathrm{day}]$ & 1322 & 1560 & 1766 & 1935 \\
Max. burnup $\left[\mathrm{MWd} / \mathrm{t}_{\mathrm{hm}}\right]$ & 52,966 & 54,020 & 55,223 & 57,025 \\
$T_{\text {scram }}^{\text {max } \mathrm{DLFC}}\left[{ }^{\circ} \mathrm{C}\right]$ & 1240 & 1448 & 1623 & 1789 \\
$\alpha_{\text {uniform }}^{+500 \mathrm{~K}}[\mathrm{pcm} / \mathrm{K}]$ & -3.52 & -3.38 & -3.28 & -3.14 \\
\hline
\end{tabular}

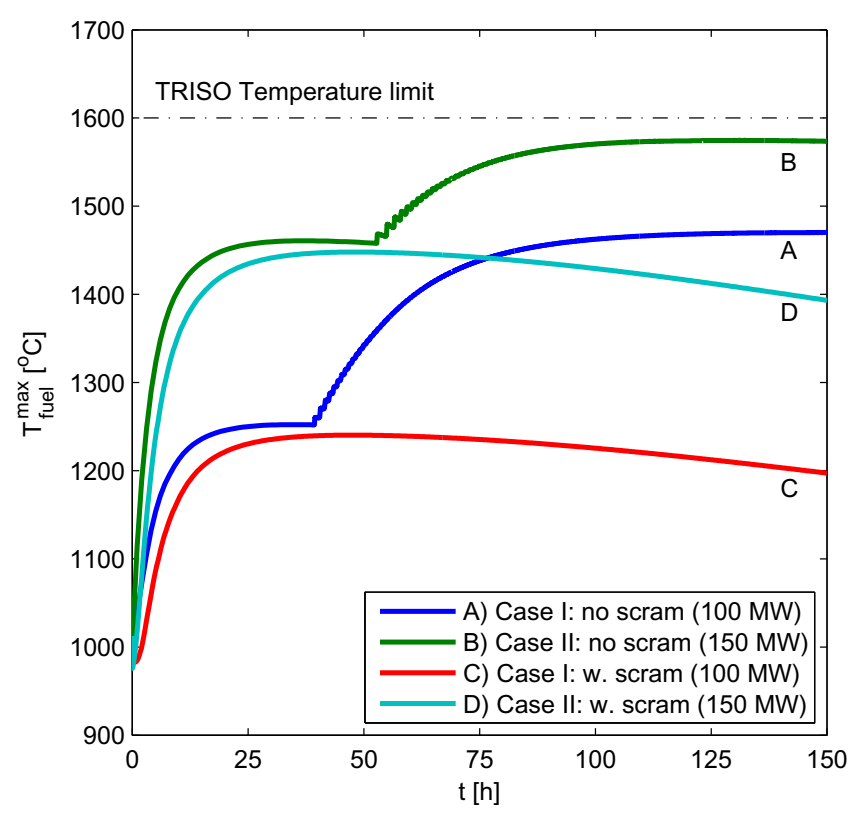

Fig. 6. Maximum fuel temperature over time during a DLOFC with and without scram for reactor powers of 100 MWth and 150 MWth in a $300 \mathrm{~cm}$ core with a $100 \mathrm{~cm}$ driver zone radius. 
150 MWth. For the transients with scram, the maximum fuel temperature increases rapidly during the initial stage of the transient and reaches its maximum after $47 \mathrm{~h}(100 \mathrm{MWth})$ or $48 \mathrm{~h}$ (150 MWth). It slowly decreases afterwards as the decay heat production becomes smaller.

For the transients without scram, the interruption of the coolant flow and depressurization of the core, heat up (the largest part of) the core and the core becomes subcritical leading to a slow decrease of the fission power. After a few minutes the power production in the core is mainly due to decay heat, which leads to a further increase of the maximum fuel temperature in the core. The additional fission power during the first minutes is the reason the temperature increase is a bit stronger during the initial stage of the transient without scram.

After $39 \mathrm{~h}$ (100 MWth) or $53 \mathrm{~h}$ (150 MWth) recriticality occurs as the positive reactivity effect of the reduced Xe-135 concentrations becomes equal to the negative reactivity effect of the temperature feedback. After the recriticality, the fission power and temperature increase rapidly, making the core subcritical till the core cools down again or a sufficient amount of xenon has decayed again to induce another fission power increase.

The maximum fuel temperatures, $1470{ }^{\circ} \mathrm{C}(100 \mathrm{MWth})$ and $1575^{\circ} \mathrm{C}(150 \mathrm{MWth})$, during the transient without scram are significantly higher than for the case with scram. For modular Pebble Bed Reactors fueled with U-235/U-238 this is generally not the case, since these reactors have stronger temperature reactivity coefficients than a thorium fueled Pebble Bed Reactor.

The difference in the maximum fuel temperature due to a power increase from 100 MWth to 150 MWth is a lot smaller in the transient without scram, as it has reduced from $228^{\circ} \mathrm{C}$ (curve $\mathrm{D}$ vs $\mathrm{C}$ in Fig. 6)) to $105^{\circ} \mathrm{C}$ (curve B vs A). This is because the decay heat production scales linearly with the nominal power of the reactor. The maximum temperature after the recriticality is also determined by the prompt fission power, which depends on the combination of the temperature feedback and the xenon reactivity effect. The temperature feedback is slightly weaker for the 150 MWth case (Table 2), while the xenon reactivity contribution only increases slightly, i.e. $+2494 \mathrm{pcm}(100 \mathrm{MWth})$ and $+2594 \mathrm{pcm}$ (150 MWth) after all Xe-135 in the steady-state core decays.

The total power production after the recriticality is shown for the $100 \mathrm{MWth}$ design in Fig. 7. The oscillations in fission power

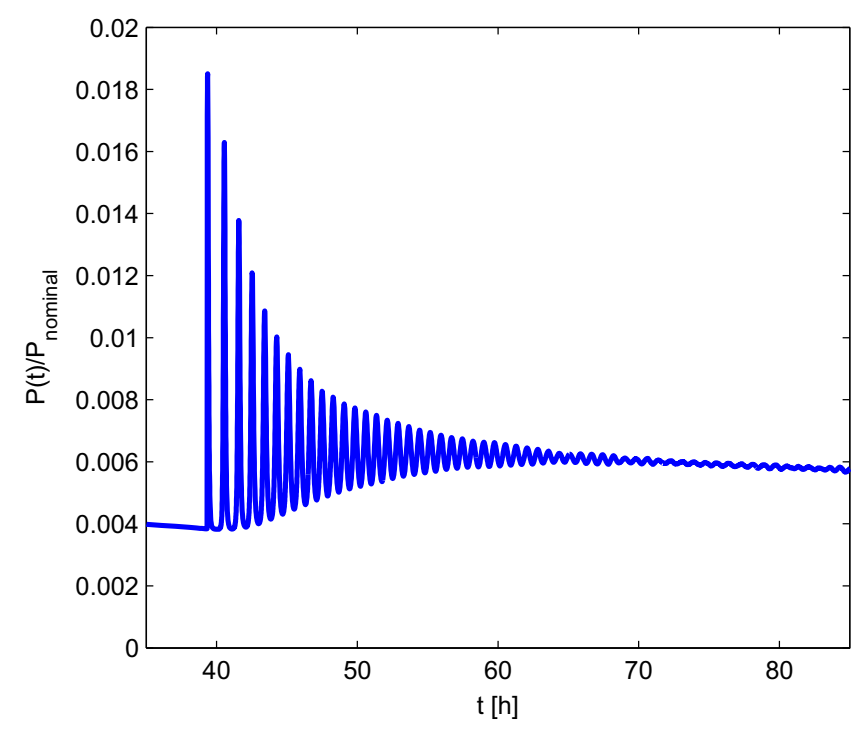

Fig. 7. Ratio between actual power (fission plus decay heat) over nominal power during the coupled transient for the 100 MWth core configuration. after the recriticality can persist for quite a long time due to the relatively slow thermal response inside a Pebble Bed Reactor (Van Dam, 1996). The phenomenon behind the power oscillations in Fig. 7 is certainly physical, but numerical difficulties in the current code scheme also cause the power oscillations to persist for quite a long time. The numerical difficulties can be seen as the oscillations do not fully damp out later in the transient, e.g. after $65 \mathrm{~h}$ in Fig. 7. It has been tested that these oscillations damp out quicker if smaller time steps are used, but this comes at a price of extremely long computation times for the full transient. So, this is unfeasible for the calculation of a significant number of transients. It is important to realize that these oscillations do not affect the trend of the maximum fuel temperature for the different designs as the temperature is physically bounded by the decay of xenon and the reactivity coefficients.

\subsection{Core radius}

A larger core radius leads to a reduction of neutron leakage and is expected to increase the conversion ratio. Table 3 shows the conversion ratio increases significantly if the core radius is increased from $200 \mathrm{~cm}$ to $250 \mathrm{~cm}$, while further extension of the core radius only leads to a marginal increase. So, core radii larger than $300 \mathrm{~cm}$ are not very interesting.

The residence time of the driver pebbles decreases for larger core radii, and consequently lower burnups are attained in the driver pebbles. The reduced residence times are somewhat surprising, but can be understood from the fact that a single concentration is used (radially) for driver and breeder zone. For larger breeder zones, the average flux and U-233 concentration in the breeder zone becomes lower and hence also the power production. So in the calculations, a larger fraction of the power is produced in the driver zone and a larger fuel insertion rate is required. This is a limitation of the current model, though it can be argued that this also occurs in reality with a larger number of breeder pebble recyclings and random reinsertion. For future studies, it would be interesting to investigate the conversion ratio using more detailed radial fuel depletion models.

The maximum fuel temperatures during a DLOFC with scram increases as the core radius increases, as shown in Fig. 8. As discussed above, the maximum power density increases for the larger core radii and also the thermal resistance for decay heat removal has increased due to the larger breeder zone radius, explaining the raise of the maximum fuel temperature. Later on in the transient, the fuel temperature also decreases slower for the larger core size. For the DLOFC without scram, the maximum fuel temperature is quite a bit lower $\left(1404^{\circ} \mathrm{C}\right.$ vs $1470{ }^{\circ} \mathrm{C}$ ) if the core radius is reduced to $200 \mathrm{~cm}$. This ensures a reasonable margin remains with the TRISO limit temperature of $1600{ }^{\circ} \mathrm{C}$, also in view of modelling uncertainties and assumptions used, but it comes at the price of a significantly lower conversion ratio.

Table 3

Overview of conversion ratio, fuel management and safety parameters for different core radii $\left(P=100[M W \mathrm{th}], T_{\text {res.tot }}^{\text {breed }}=2000[\mathrm{~d}], \epsilon_{\text {driver }}^{U-233, \text { in }}=12[\mathrm{~W} \%], R_{\text {driver }}=100[\mathrm{~cm}], 15\right.$ driver pebble passes and 2 breeder pebble passes).

\begin{tabular}{lllll}
\hline Case & I & II & III & IV \\
Core radius $[\mathrm{cm}]$ & 200 & 250 & 300 & 350 \\
\hline Conversion ratio & 0.9597 & 0.9870 & 0.9913 & 0.9921 \\
$T_{\text {res,tot }}^{\text {driver }}[\mathrm{d}]$ & 427 & 356 & 323 & 306 \\
$P_{\text {density }}^{\max }\left[\mathrm{MW} / \mathrm{m}^{3}\right]$ & 4.9 & 5.6 & 6.2 & 6.5 \\
Pebble handling time $[\mathrm{s}]$ & 12.2 & 9.8 & 8.5 & 7.7 \\
Reprocessing rate $[\mathrm{p} / \mathrm{day}]$ & 716 & 1012 & 1322 & 1658 \\
Max. burnup $\left[\mathrm{MWd} / \mathrm{t}_{\mathrm{hm}}\right]$ & 62,459 & 56,060 & 52,996 & 51,412 \\
$T_{\text {scram }}^{\text {max } \mathrm{DLOFC}}\left[{ }^{\circ} \mathrm{C}\right]$ & 1161 & 1211 & 1240 & 1259 \\
$\alpha_{\text {uniform }}^{+500}[\mathrm{pcm} / \mathrm{K}]$ & -3.41 & -3.52 & -3.52 & -3.51 \\
\hline
\end{tabular}




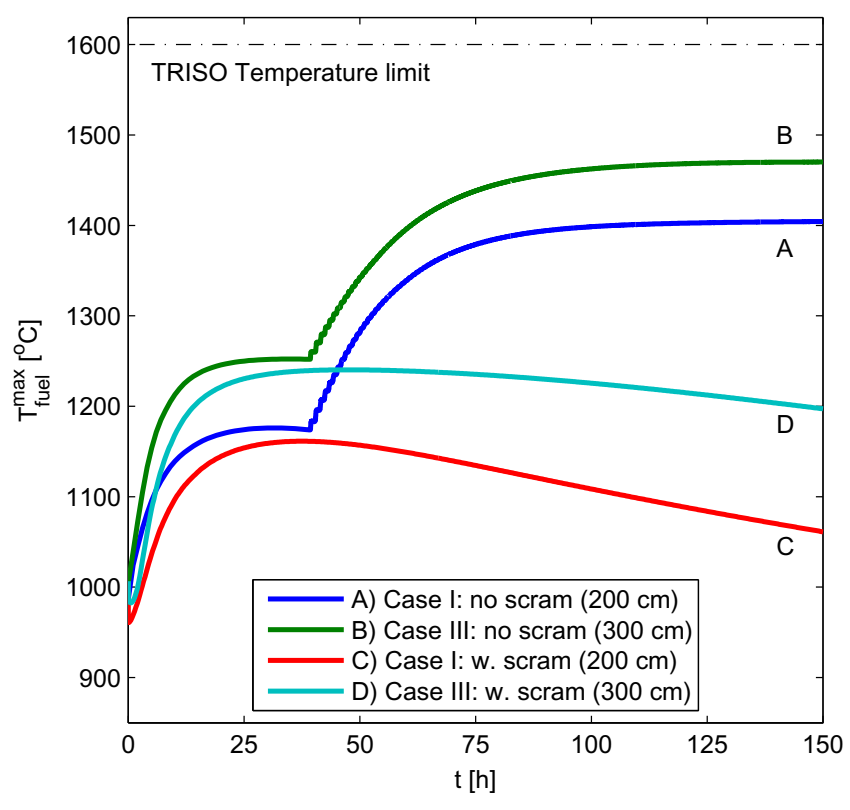

Fig. 8. Maximum fuel temperature over time during a DLOFC with and without scram for core radii of $200 \mathrm{~cm}$ and $300 \mathrm{~cm}$ with a $100 \mathrm{~cm}$ driver zone radius and a 100 MWth nominal power.

\subsection{Driver zone radius}

Besides the core radius, which should be sufficiently large to reduce neutron leakage, the driver zone radius has a large influence upon the conversion ratio, as shown in Table 4. Enlarging the driver zone radius from $100 \mathrm{~cm}$ to $110 \mathrm{~cm}(P=100 \mathrm{MWth})$ leads to a significant reduction of the conversion ratio, from 0.9913 to 0.9616 , while a reduction of the driver zone radius to $90 \mathrm{~cm}$ leads to an increase of the conversion ratio to 1.0328 , at the price of a very high pebble handling speed requirement. This is around five times faster than the average fuel handling speed of the HTR-PM, where a single pebble is handled each $14.52 \mathrm{~s}$ (see Section 4.6). This may provide a big engineering challenge. The reprocessing rate also increases significantly for a smaller driver zone radius, which is also marked by the low burnup (16.8 $\mathrm{GWd} / \mathrm{t}_{h m}$ ) attained in the driver pebbles.

Another important issue of a smaller driver zone radius is that the temperature feedback becomes weaker, as the driver zone becomes more undermoderated due to the higher average U-233 weight fraction caused by the increased pebble handling speed. An undermoderated state of the driver zone also makes the core more vulnerable to water ingress.

Fig. 9 shows the maximum fuel temperature during a DLOFC with and without scram for the different driver zone radii

\section{Table 4}

Overview of conversion ratio, fuel management and safety parameters for different driver zone radii $\left(P=100[\mathrm{MW}\right.$ th $], T_{\text {rees }}^{\text {breed }}=2000[\mathrm{~d}], \epsilon_{\text {driver }}^{U-233}=12[\mathrm{w} \%], R_{\text {core }}=$ $300[\mathrm{~cm}], 15$ driver pebble passes and 2 breeder pebble passes).

\begin{tabular}{llll}
\hline Case & I & II & III \\
Driver zone radius $[\mathrm{cm}]$ & 90 & 100 & 110 \\
\hline Conversion ratio & 1.0328 & 0.9913 & 0.9616 \\
$T_{\text {res,tot }}^{\text {diver }}[\mathrm{d}]$ & 84 & 323 & 581 \\
$P_{\text {density }}^{\max }\left[\mathrm{MW} / \mathrm{m}^{3}\right]$ & 7.1 & 6.2 & 5.6 \\
Pebble handling time [s] & 3.0 & 8.5 & 11.9 \\
Reprocessing rate $[\mathrm{p} / \mathrm{day}]$ & 2561 & 1322 & 1114 \\
Max. burnup $\left[\mathrm{MWd} / \mathrm{t}_{\mathrm{hm}}\right]$ & 16,800 & 52,996 & 79,381 \\
$T_{\text {scram }}^{\max \text { DLFC }}\left[{ }^{\circ} \mathrm{C}\right]$ & 1257 & 1240 & 1237 \\
$\alpha_{\text {uniform }}^{+500 \mathrm{~K}}[\mathrm{pcm} / \mathrm{K}]$ & -3.22 & -3.52 & -3.82 \\
\hline
\end{tabular}

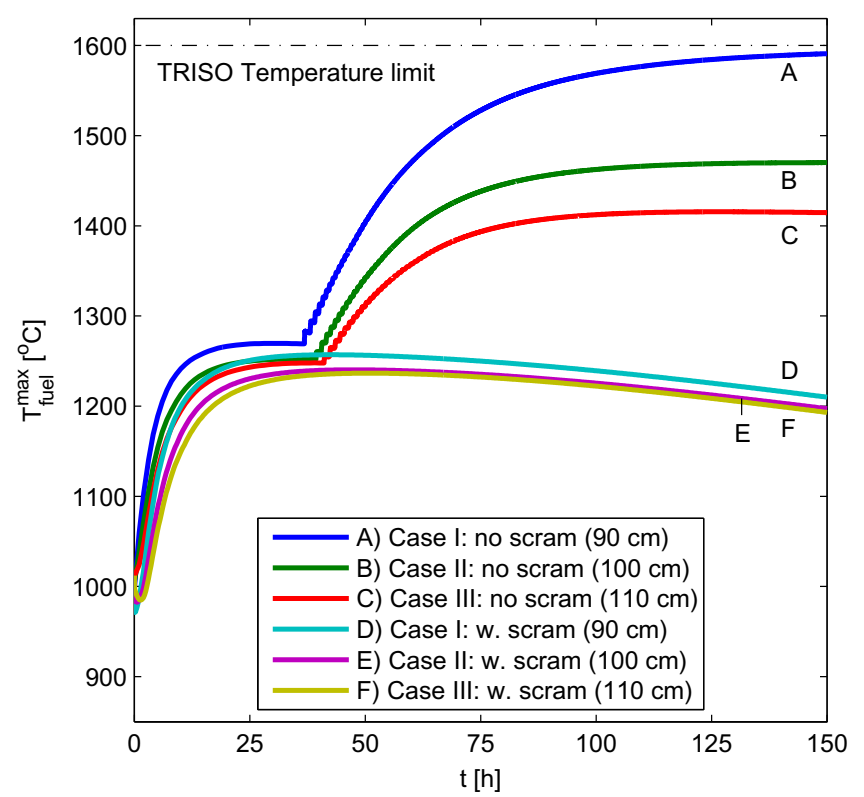

Fig. 9. Maximum fuel temperature over time during a DLOFC with and without scram for driver zone radii of 90,100 and $110 \mathrm{~cm}$ and a core radius of $300 \mathrm{~cm}$.

considered. The differences for the transient with scram are quite small, with the highest maximum fuel temperature occurring for the smallest driver zone. For the transient without scram, the maximum fuel temperature becomes significantly higher with a smaller driver zone due to the weaker temperature feedback and higher power density, which also results in higher steady-state Xe-135 concentrations.

For all three driver zone radii the maximum fuel temperature still remains below $1600{ }^{\circ} \mathrm{C}$, but the $90 \mathrm{~cm}$ driver zone comes very close to this limit, also keeping in mind the modelling assumptions made, which will be addressed in Section 6. Another issue, the high pebble handling speed with a $90 \mathrm{~cm}$ driver zone, may be resolved by using less driver pebble passes and by using a higher U-233 weight fraction in the driver pebbles. Less driver pebble passes leads to a higher axial power peaking, while a higher U-233 content per driver pebble might reduce the temperature feedback further and cause difficulties in case of water ingress. From this perspective, safety and breeding act in opposite directions. So, it remains to be seen whether a compromise involving breeding and passive safety within practical constraints is possible.

\subsection{Number of driver pebble passes}

The handling time per pebble was quite short in most of the results till now. From a practical perspective, it would be desirable to avoid pebble handling speeds (significantly) above those in the HTR-PM. A single 250 MWth HTR-PM core contains 420,000 pebbles with a $7 \mathrm{~g}$ HM loading and the average burnup of discharged pebbles is $90 \mathrm{GWd} / t_{h m}$ (Zheng et al., 2009). This means the average pebble resides for 1058 days in the core. Each day the HTR-PM discards 397 depleted fuel pebbles. Since each pebble makes 15 passes through the core the fuel handling system has to be capable of handling a pebble each $14.52 \mathrm{~s}$ on average. All of the configurations presented so far require a faster pebble handling speed than the HTR-PM. The pebble flow rate can be reduced by lowering the number of recyclings of the driver pebbles. The impact of using 6 or 10 , instead of 15 , driver pebble passes upon the conversion ratio and decay heat removal is shown in Table 5 .

The use of a lower number of driver pebble passes hardly influences the conversion ratio and the handling time per pebble is significantly slower. With 6 passes it is slower than the 
Table 5

Overview of conversion ratio, fuel management and safety parameters for differen number of driver pebble passages $\left(P=100[\mathrm{MW}\right.$ th $], T_{\text {rees }}^{\text {bred }}=2000[d], \epsilon_{\text {driver }}^{U-233, \text { in }}=$ $12[\mathrm{w} \%], R_{\text {core }}=300[\mathrm{~cm}], R_{\text {driver }}=100[\mathrm{~cm}], 2$ breeder pebble passes).

\begin{tabular}{llll}
\hline Case & I & II & III \\
Driver pebble passes & 6 & 10 & 15 \\
\hline Conversion ratio & 0.9908 & 0.9912 & 0.9913 \\
$T_{\text {res,tot }}^{\text {driver }}[\mathrm{d}]$ & 317 & 321 & 323 \\
$P_{\text {density }}^{\max }\left[\mathrm{MW} / \mathrm{m}^{3}\right]$ & 6.9 & 6.4 & 6.2 \\
Pebble handling time [s] & 17.2 & 11.8 & 8.5 \\
Reprocessing rate $[\mathrm{p} / \mathrm{day}]$ & 1334 & 1326 & 1322 \\
Max. burnup [MWd $\left./ \mathrm{t}_{\mathrm{hm}}\right]$ & 51,961 & 52,677 & 52,966 \\
$T_{\text {scram }}^{\max \text { DLFC }}\left[{ }^{\circ} \mathrm{C}\right]$ & 1285 & 1256 & 1240 \\
$\alpha_{\text {uniform }}^{+500 \mathrm{~K}}[\mathrm{pcm} / \mathrm{K}]$ & -3.53 & -3.53 & -3.52 \\
\hline
\end{tabular}

requirement of the HTR-PM's fuel handling system. A lower number of passes reduces the flattening of the power profile and makes decay heat removal a bit worse $\left(+45^{\circ} \mathrm{C}\right.$ for 6 passes), while the reactivity coefficients are hardly influenced.

The impact of using 6 instead of 15 driver pebble passes upon the DLOFC temperatures with and without scram is shown in Fig. 10. Without scram, the maximum fuel temperature increase is only $15^{\circ} \mathrm{C}$. So, the pebble handling speed can be reduced safely to meet the specifications of the fuel handling system of the HTRPM design, with a $100 \mathrm{~cm}$ driver zone radius. However, a smaller driver zone radius $(90 \mathrm{~cm})$ is required to increase the conversion ratio above one. In that case a sufficient reduction of the pebble handling speed may only be achieved by an increase of the U233 content in the driver pebbles, but this weakens the temperature feedback.

\subsection{Breeder pebble residence time}

A breeder pebble residence time shorter than 2000 days leads to a slight decrease of the conversion ratio for a $300 / 100 \mathrm{~cm}$ core configuration operating at 100 MWth power, as shown in Table 6.

The handling speed of the driver pebbles and the maximum power density increases due to the lower fissile content and power production in the breeder zone. This also results in slightly higher maximum fuel temperatures during a DLOFC with scram.

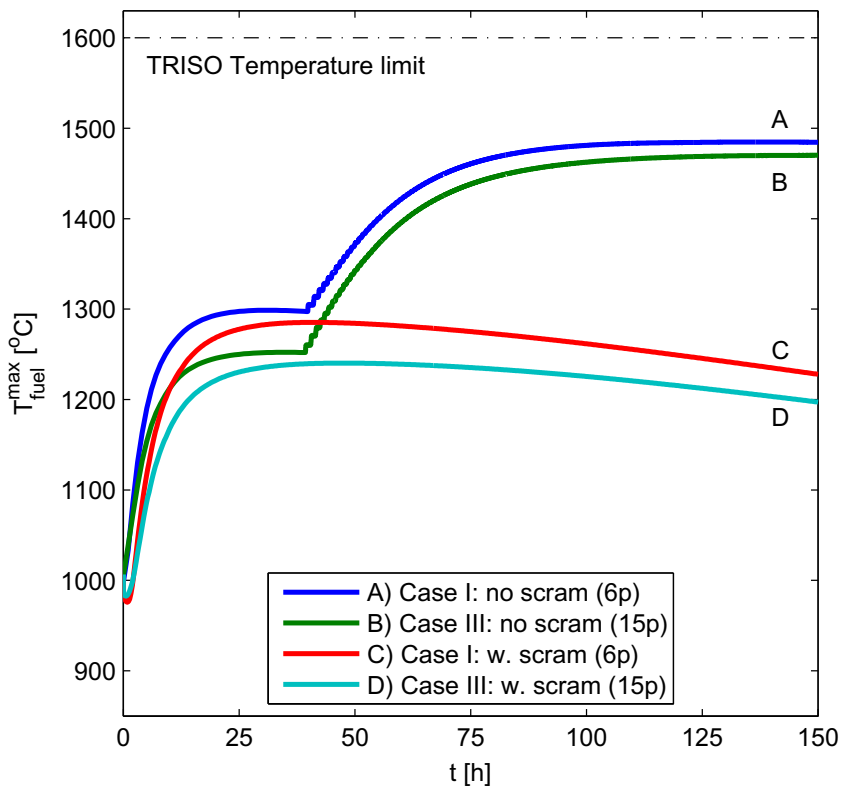

Fig. 10. Maximum fuel temperature over time during a DLOFC with and without scram for 6 and 15 driver pebble passes for a core with a $100 \mathrm{~cm}$ driver zone and a $300 \mathrm{~cm}$ core radius.
Table 6

Overview of conversion ratio, fuel management and safety parameters for different breeder pebble residence times, $\left(P=100[\mathrm{MWth}], \epsilon_{\text {driver }}^{U-233, i n}=12[\mathrm{~W} \%], R_{\text {core }}=\right.$ $300[\mathrm{~cm}], R_{\text {driver }}=100[\mathrm{~cm}], 6$ driver pebble passes and 2 breeder pebble passes).

\begin{tabular}{|c|c|c|c|}
\hline $\begin{array}{l}\text { Case } \\
T_{\text {res,tot }}^{\text {breed }}[\mathrm{d}]\end{array}$ & $\begin{array}{l}\text { I } \\
1000\end{array}$ & $\begin{array}{l}\text { II } \\
1500\end{array}$ & $\begin{array}{l}\text { III } \\
2000\end{array}$ \\
\hline Conversion ratio & 0.9850 & 0.9893 & 0.9913 \\
\hline$T_{\text {res,tot }}^{\text {driver }}[\mathrm{d}]$ & 279 & 300 & 317 \\
\hline$P_{\text {density }}^{\max }\left[\mathrm{MW} / \mathrm{m}^{3}\right]$ & 7.5 & 7.2 & 6.9 \\
\hline Pebble handling time [s] & 12.4 & 15.1 & 17.2 \\
\hline Reprocessing rate [p/day] & 2159 & 1615 & 1334 \\
\hline Max. burnup [MWd/ $\left.\mathrm{t}_{\mathrm{hm}}\right]$ & 47,904 & 50,364 & 51,961 \\
\hline$T_{\text {scram }}^{\max \text { DLOFC }}\left[{ }^{\circ} \mathrm{C}\right]$ & 1319 & 1303 & 1285 \\
\hline$\alpha_{\text {uniform }}^{+500 \mathrm{~K}}[\mathrm{pcm} / \mathrm{K}]$ & -3.49 & -3.51 & -3.53 \\
\hline
\end{tabular}

The difference in maximum temperature is of similar magnitude for a DLOFC without scram, as shown in Fig. 11. So, both from the perspectives of the conversion ratio, safety, the reprocessing rate and the fuel handling system, a longer breeder pebble residence time of 2000 days would be desirable. Nonetheless, a breeder pebble residence time of 1000 or 1500 days is more feasible from a practical perspective as it also reduces the length of the running-in phase of the reactor, especially in relation to the lifetime of a typical reactor.

\section{Design choices}

The previous section has given an overview of the impact of several core design and fuel management parameters upon the conversion ratio, passive safety and the requirement of the fuel handling system. Based on these results, different core designs with either improved conversion ratio $(>1)$ or improved passive safety within practical constraints are investigated, as well as the potential to combine both of these goals.

\subsection{Improving the conversion ratio}

The results in Table 4 give a clear indication that a significant increase of the conversion ratio can be achieved by reducing the driver zone radius to $90 \mathrm{~cm}$. On the downside the driver pebble

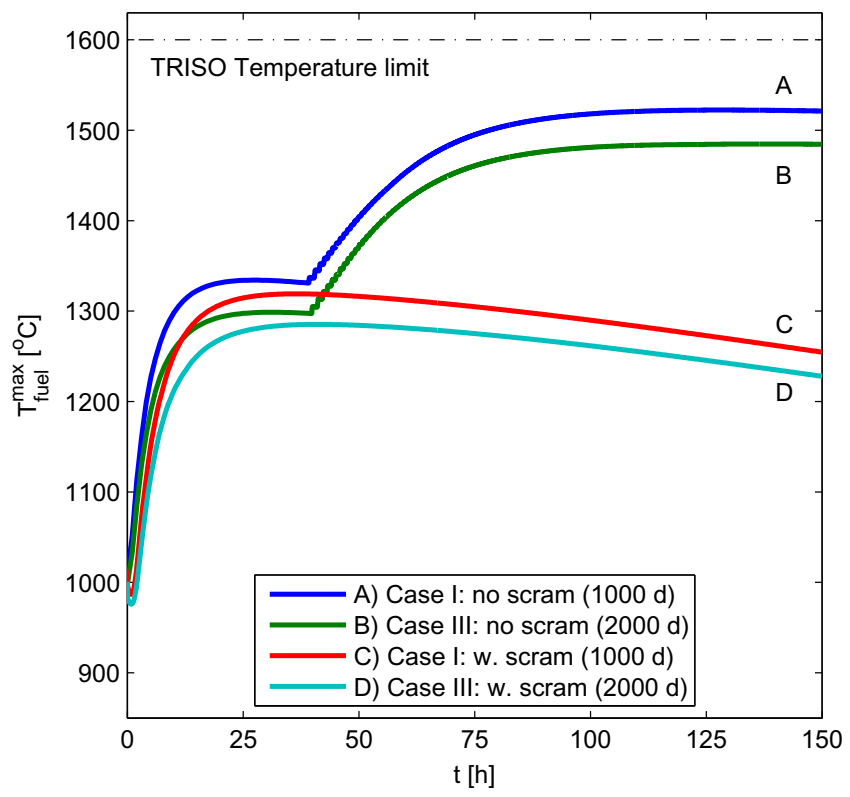

Fig. 11. Maximum fuel temperature over time during a DLOFC with and without scram for a 1000 and 2000 days breeder pebble residence time for a core with a $100 \mathrm{~cm}$ driver zone and a $300 \mathrm{~cm}$ core radius. 
residence time becomes very short, so the fuel handling system would need to handle one pebble every $3 \mathrm{~s}$, as compared to the $14.52 \mathrm{~s}$ of the HTR-PM. Though it may be possible to construct a fuel handling system capable of such short handling times $(3 \mathrm{~s})$, e.g. by using multiple outlets, a reduction of the pebble handling speed is preferable from an engineering perspective. The pebble handling speed can be reduced by limiting the number of driver pebble passages to six and by increasing the U-233 weight fraction of the driver pebbles. These options are investigated in Table 7.

Case II shows that an increase of the U-233 content of the driver pebbles and a reduction of the number of driver pebble passes to six, lead to a slight reduction of the conversion ratio ( $C R=1.0072$ ) as compared to case I, which was already presented in Table 4. The handling time per pebble has significantly increased and is feasible from an engineering perspective, i.e. the handling speed is slower than for the HTR-PM. The reprocessing rate is also significantly reduced by the higher U-233 content of the driver pebbles, which is also marked by the higher burnup attained in the driver pebbles. Although the power density increases a bit, but the maximum fuel temperature during a DLOFC with scram is still far below $1600^{\circ} \mathrm{C}$. A bigger concern is caused by the weaker temperature feedback, which could cause fuel element temperatures to exceed $1600{ }^{\circ} \mathrm{C}$ during a DLOFC without scram.

Case III adds to this an increase of the core power to $120 \mathrm{MWth}$ in conjunction with a reduction of the breeder pebble residence time to 1500 days, for economical and practical considerations. These changes only have a limited effect on the conversion ratio, which is still above one, and lead to a slightly higher power density and maximum fuel element temperature during a DLOFC with scram, but still $172{ }^{\circ} \mathrm{C}$ below the failure temperature of the TRISO particles. But some margin should also remain in consideration of modelling uncertainties and assumptions in the relatively coarse models used for the parametric studies in this work. Improved decay heat models, i.e. specific data for U-233 and including the influence of pebble movement upon the power history of the pebbles, and more radially detailed fuel depletion models may cause an increase of maximum fuel temperatures, but they could also decrease.

Case IV considers a further increase of the U-233 content of the driver pebbles to $18 \mathrm{w} \%$, in combination with a further reduction of the driver pebble radius to $80 \mathrm{~cm}$. This increases the conversion ratio to 1.0268 , while the handling time per pebble is still acceptable, as well as the maximum fuel element temperature $\left(1423^{\circ} \mathrm{C}\right)$ during a DLOFC with scram. The main problem of this design, is the significant reduction of the temperature feedback, which means overheating is likely to become a problem in case of a (long-term)

\section{Table 7}

Overview of conversion ratio, fuel management and safety parameters for different core configurations with a smaller driver zone radius and higher U-233 weight fraction of the driver fuel, ( $R_{\text {core }}=300[\mathrm{~cm}], 2$ breeder pebble passes).

\begin{tabular}{|c|c|c|c|c|}
\hline Case & I & II & III & IV \\
\hline$R_{\text {driver }}[\mathrm{cm}]$ & 90 & 90 & 90 & 80 \\
\hline$\epsilon_{\text {driver }}^{U-233, \text { in }}[\mathrm{w} \%]$ & 12 & 15 & 15 & 18 \\
\hline Driver pebble passes & 15 & 6 & 6 & 6 \\
\hline$T_{\text {res,tot }}^{\text {breed }}[\mathrm{d}]$ & 2000 & 2000 & 1500 & 1500 \\
\hline$P[M W$ th $]$ & 100 & 100 & 120 & 120 \\
\hline Conversion ratio & 1.0328 & 1.0072 & 1.0044 & 1.0268 \\
\hline$T_{\text {res,tot }}^{\text {driver }}[\mathrm{d}]$ & 84 & 315 & 250 & 161 \\
\hline$P_{\text {density }}^{\max }\left[\mathrm{MW} / \mathrm{m}^{3}\right]$ & 7.1 & 8.0 & 9.8 & 10.6 \\
\hline Pebble handling time [s] & 3.0 & 19.6 & 15.3 & 13.3 \\
\hline Reprocessing rate $[\mathrm{p} /$ day] & 2561 & 1242 & 1621 & 1776 \\
\hline Max. burnup [MWd/thm & 16,800 & 63,397 & 61,104 & 49,593 \\
\hline$T_{\text {scram }}^{\max , \mathrm{DLOFC}}\left[{ }^{\circ} \mathrm{C}\right]$ & 1257 & 1310 & 1428 & 1423 \\
\hline$\alpha_{\text {uniform }}^{+500 K}[\mathrm{pcm} / \mathrm{K}]$ & -3.22 & -2.89 & -2.80 & -2.05 \\
\hline
\end{tabular}

failure to scram the reactor. Though such an event is extremely unlikely, it is a requirement to call a reactor passively safe.

Since the conversion ratio of the last design $(C R=1.0268)$ is a bit above one, there is some margin to reduce the core radius, and thus reduce costs, and the breeder pebble residence time. Some options are shown in Table 8.

Table 8 shows that a reduction of the core radius to $250 \mathrm{~cm}$ $(C R=1.0224$, case $\mathrm{I})$ and $220 \mathrm{~cm}(\mathrm{CR}=1.0119$, case II) can be performed while maintaining breeding. For a $200 \mathrm{~cm}$ radius, the conversion ratio $(=0.9982)$ drops below one due to the increased neutron leakage. For a $220 \mathrm{~cm}$ core radius, a reduction of the breeder pebble residence time to 1000 days leads to a small increase of the conversion ratio to 1.0135 (case III). This is different than the trend observed in Table 6 for a $300 \mathrm{~cm}$ core, due to the higher average U-233 and Pa-233 concentrations in the smaller breeder zone of the $220 \mathrm{~cm}$ core. Case IV of Table 8 shows the reactor power can be increased to $150 \mathrm{MWth}$, as compared to case II, without compromising breeding $(C R=1.0091)$. Furthermore, the maximum fuel temperature during a DLOFC with scram still remains quite a bit below $1600{ }^{\circ} \mathrm{C}$. The handling time per pebble is also acceptable.

Fig. 12 shows the maximum fuel temperature for case I and III of Table 7 and case III of Table 8 after a DLOFC with and without scram. As discussed, the DLOFC with scram does not pose a problem for any of these designs. Without scram, the maximum fuel temperature remains below the TRISO limit temperature only for the design with $12 \mathrm{w} \%$ driver pebbles, but only by less than $10^{\circ} \mathrm{C}$. In view of the modelling assumptions, this does not offer real certainty that fuel temperatures will indeed remain below $1600{ }^{\circ} \mathrm{C}$ in reality. On the other hand, slightly exceeding $1600{ }^{\circ} \mathrm{C}$ does not necessarily lead to a (significant) release of radioactive fission products from the fuel kernels, especially for relatively low burnups (Schenk et al., 1990). For the other two designs, the temperature feedback is not strong enough to compensate the reactivity increase due to the xenon decay without exceeding the TRISO temperature limit. So, active reactivity control measures are required during a DLOFC event.

So, in view of the conversion ratio, reactor size, demand on the fuel pebble handling system and practical value of the breeder pebble residence time, the last two designs of Table 8 are promising thorium breeder PBR design options. A major drawback is that safety cannot be achieved by fully passive means, because of the relatively small temperature feedback. Another potential risk is that water ingress causes a large reactivity insertion due to the undermoderated state of the driver zone. So choosing one of these breeder configurations for future design studies, places a very high demand on the reactivity control system, in terms of reliability and control rod worth.

\section{Table 8}

Overview of conversion ratio, fuel management and safety parameters for different core configurations with an $80 \mathrm{~cm}$ driver zone radius and a $18 \mathrm{w} \% \mathrm{U}-233$ weight fraction of the driver fuel, 6 driver and 2 breeder pebble passes).

\begin{tabular}{lllll}
\hline Case & I & II & III & IV \\
\hline$R_{\text {core }}[\mathrm{cm}]$ & 250 & 220 & 220 & 220 \\
$T_{\text {res, } \text { tot }}^{\text {breed }}[\mathrm{d}$ & 1500 & 1500 & 1000 & 1500 \\
$P[$ MWth] & 120 & 120 & 120 & 150 \\
Conversion ratio & 1.0224 & 1.0119 & 1.0135 & 1.0091 \\
$T_{\text {res,tot }}^{\text {driver }}[\mathrm{d}]$ & 185 & 203 & 171 & 177 \\
$P_{\text {density }}^{\text {max }}\left[\mathrm{MW} / \mathrm{m}^{3}\right]$ & 9.9 & 9.2 & 10.1 & 10.7 \\
Pebble handling time $[\mathrm{s}]$ & 16.4 & 18.9 & 15.0 & 17.0 \\
Reprocessing rate $[\mathrm{p} / \mathrm{day}]$ & 1343 & 1110 & 1482 & 1195 \\
${\text { Max. burnup }\left[\mathrm{MWd} / \mathrm{t}_{\mathrm{hm}}\right]}_{T_{\text {scram }}^{\text {max } \text { DLFC }}\left[{ }^{\circ} \mathrm{C}\right]}^{54,325}$ & 57,626 & 51,197 & 60,623 \\
$\alpha_{\text {uniform }}^{+500 \mathrm{~K}}[\mathrm{pcm} / \mathrm{K}]$ & 1389 & 1358 & 1400 & 1474 \\
\hline
\end{tabular}




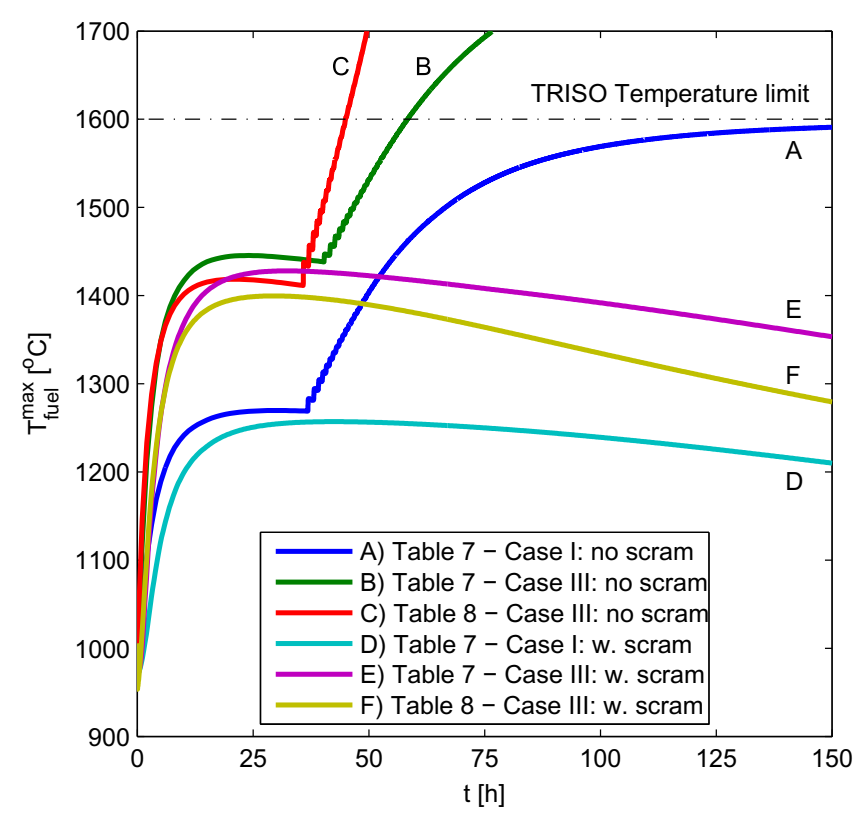

Fig. 12. Maximum fuel temperature over time during a DLOFC with and without scram for cases I and III of Table 7 and case III of Table 8.

\subsection{Improving passive safety}

The main problem in terms of passive safety of a thorium breeder PBR is the weak reactivity feedback. The reactivity feedback becomes stronger for a lower U-233 weight fraction in the driver fuel. This section investigates the use of a $10 \mathrm{w} \% \mathrm{U}-233$ fraction per driver pebble. The disadvantage is that the fuel pebble handling speed increases significantly. So, the driver zone radius cannot be too small $(\geqslant 100 \mathrm{~cm})$, which may limit the breeding potential of such designs. On the other hand, as shown by cases I and II of Table 7, a lower U-233 weight fraction can also have a positive effect on the conversion ratio.

Four different core designs are considered in Table 9. Case I and II have a driver zone radius of $100 \mathrm{~cm}$ and a core radius of $300 \mathrm{~cm}$. These configurations are breeders $(C R>1)$ and have relatively strong reactivity coefficients $(-3.67 \mathrm{pcm} / \mathrm{K})$. The number of driver pebble passes is reduced from 6 to 4 in case II. This helps to reduce the fuel pebble handling speed and only has limited influence on the maximum fuel temperature during a DLOFC with scram $\left(+12{ }^{\circ} \mathrm{C}\right)$. These values for the maximum fuel temperatures are still far below the maximum TRISO failure temperature of $1600^{\circ} \mathrm{C}$. The fuel pebble handling speed for case II is still more than twice as fast

\section{Table 9}

Overview of conversion ratio, fuel management and safety parameters for different core configurations with $P=100 \mathrm{MWth}, T_{\text {res }}^{\text {breed }}=1000$ [d], $10 \mathrm{w} \% \mathrm{U}-233$ in the $3 \mathrm{~g} \mathrm{HM}$ driver pebbles, a $100 \mathrm{~cm}$ driver zone radius, 6 driver and 2 breeder pebble passes).

\begin{tabular}{lllll}
\hline Case & I & II & III & IV \\
\hline$R_{\text {core }}[\mathrm{cm}]$ & 300 & 300 & 300 & 250 \\
$R_{\text {driver }}[\mathrm{cm}]$ & 100 & 100 & 110 & 110 \\
Driver passes & 6 & 4 & 6 & 5 \\
Conversion ratio & 1.0037 & 1.0036 & 0.9708 & 0.9660 \\
$T_{\text {res,tot }}^{\text {driver }}[\mathrm{d}]$ & 81.8 & 80.4 & 293.6 & 306.2 \\
$P_{\text {density }}^{\text {max }}\left[\mathrm{MW} / \mathrm{m}^{3}\right.$ ] & 6.7 & 6.9 & 6.5 & 6.3 \\
Pebble handling time $[\mathrm{s}]$ & 5.2 & 7.0 & 11.5 & 15.5 \\
Reprocessing rate $[\mathrm{p} / \mathrm{day}]$ & 3770 & 3810 & 2220 & 1676 \\
Max. burnup $\left[\mathrm{MWd} / \mathrm{t}_{\mathrm{hm}}\right]$ & 14,017 & 13,778 & 41,763 & 42,698 \\
$T_{\text {scram }}^{\text {max.DLFC }}\left[{ }^{\circ} \mathrm{C}\right]$ & 1268 & 1280 & 1288 & 1280 \\
$\alpha_{\text {uniform }}^{+500 \mathrm{~K}}[\mathrm{pcm} / \mathrm{K}]$ & -3.67 & -3.67 & -3.93 & -3.90 \\
\hline
\end{tabular}

as in the regular HTR-PM design, but this engineering challenge seems inevitable for a breeder design with a sufficiently strong reactivity coefficient. An economical challenge might be posed by the enormous increase of the required reprocessing rate, which has more than tripled per unit of energy produced as compared to the case III of Table 8 .

Case III has a $300 \mathrm{~cm}$ core radius and a $110 \mathrm{~cm}$ driver zone radius. The increased size of the driver zone leads to a reduction of the conversion ratio to 0.9708 , but does contribute to a slightly stronger reactivity coefficient $(-3.93 \mathrm{pcm} / \mathrm{K})$. Case IV is still a highconversion reactor $(C R=0.9660)$ with a relatively strong reactivity coefficient and a fuel pebble handling speed similar to the HTR-PM.

The maximum fuel temperature during a DLOFC with and without scram is shown in Fig. 13 for case II and case IV of Table 9. With scram, the maximum fuel temperature is the same for these designs, but the smaller core cools down more rapidly later on in the transient. During a DLOFC with scram the smaller core also profits from its smaller core radius and the stronger reactivity feedback. In both cases the maximum fuel temperature, i.e. $1481{ }^{\circ} \mathrm{C}$ and $1430^{\circ} \mathrm{C}$ respectively, remain quite a bit below the TRISO failure temperature.

One final remark should be made about the reactivity effect of the decaying Pa-233, which has been neglected in the transient calculations in this work. For case II of Table 9, a complete decay of the Pa-233 into $\mathrm{U}-233$, would result in a reactivity addition of $466 \mathrm{pcm}$. In reality, around $15 \%$ of the Pa-233 has decayed after $150 \mathrm{~h}$, so an additional reactivity effect of $+69 \mathrm{pcm}$ may be anticipated from linear interpolation. A complete decay of Xe-135 results in a reactivity effect of $+2531 \mathrm{pcm}$. So, for this case, neglecting the Pa-233 effect does not have a large impact upon the results of the transient.

\subsection{Water ingress}

Besides the response to a DLOFC with and without scram, the maximum possible reactivity insertion due to water ingress is an important safety aspect. In a worst case scenario, such an ingress of water vapour would occur in combination with a DLOFC without scram. Ideally, for complete passive safety, the temperature

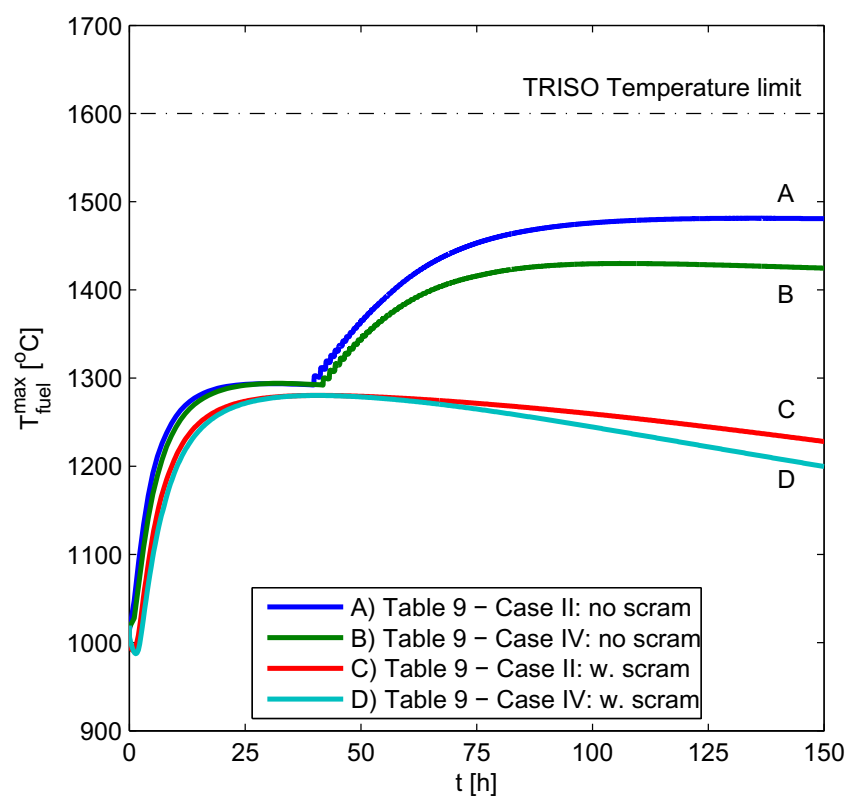

Fig. 13. Maximum fuel temperature over time during a DLOFC with and without scram for cases II and IV of Table 9. 
feedback can overcome both the reactivity insertion due to water ingress and xenon decay. But this is a very strict demand, since water ingress and xenon decay occur at completely different time-scales. The water ingress is an almost instantaneous effect, while xenon causes a reactivity increase after many hours.

To minimize the risks caused by water ingress, the temperature feedback has to be quite strong or the reactivity insertion due to water ingress has to be very small (or negative), which requires the driver zone to be around an optimal to overmoderated state. However, the temperature feedback of the HTR-PM design is not sufficient to compensate for a worst-case water ingress, as can be observed in the work by Zheng et al. (2010). In the HTR-PM, the maximum reactivity increase due to water ingress is around 4.3\%. According to Zheng et al. (2010), the fuel temperature feedback coefficient of $-4.36 \cdot 10^{-5} \Delta \mathrm{k} / \mathrm{k} /{ }^{\circ} \mathrm{C}$ can compensate around $3 \%$ of this $4.3 \%$ by a temperature increase without exceeding the TRISO coating's temperature limit of $1600^{\circ} \mathrm{C}$. The remaining reactivity increase (1.3\%) due to water ingress would have to be compensated by the reflector rods.

Fig. 14 shows the reactivity insertion due to an ingress of water vapour for three promising thorium PBR configurations. The water density is specified in $\mathrm{kg} / \mathrm{m}^{3}$ of the total core volume, so the helium volume plus the pebble volume. These calculations were performed in the same way as in previous work by the authors (Wols et al., 2014b).

The maximum reactivity insertion is $+6147 \mathrm{pcm}$ for the first configuration, with an $80 \mathrm{~cm}$ driver zone radius and $18 \mathrm{w} \% \mathrm{U}-233$ per fresh driver fuel pebble (Table 8 - case III). The high average $\mathrm{U}-233$ weight fraction of the driver pebbles makes the driver zone strongly undermoderated, so a large reactivity insertion occurs if water vapour enters the primary loop. A reactivity increase of $6147 \mathrm{pcm}$ cannot be compensated by the temperature feedback and thus puts a large demand on the required reactivity worth of the reactivity control system, i.e. the control rods and absorber balls. Furthermore, this system is also not passively safe in case of a water ingress, as was also the case during a DLOFC without scram (see Fig. 12). Nonetheless, the design might still be interesting in view of the relatively small core radius for which breeding

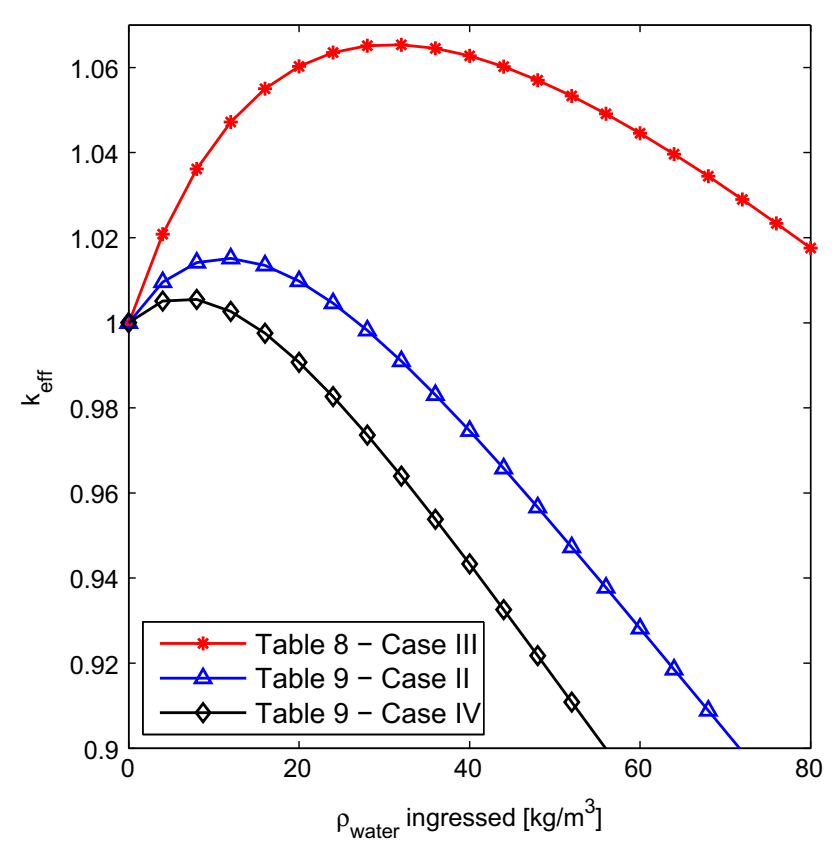

Fig. 14. $\mathrm{k}_{\text {eff }}$ as a function of water ingressed $\left[\mathrm{kg} / \mathrm{m}^{3}\right.$ of the total core volume] for three promising core designs. can be achieved within practical constraints, i.e. fuel pebble handling speed and breeder pebble residence time.

For the second configuration (Table 9 - case II), which combines breeding and a maximum fuel temperature below $1600{ }^{\circ} \mathrm{C}$ during a DLOFC without scram, the maximum reactivity increase due to water ingress is limited to $1497 \mathrm{pcm}$. Compared to the first case, the average $U-233$ weight fraction is much lower in the driver zone with $10 \mathrm{w} \% \mathrm{U}-233$ in the fresh driver pebbles, and the core is only slightly undermoderated. Contrary to the first case and the HTR$\mathrm{PM}$, a reactivity insertion of $1497 \mathrm{pcm}$ can be compensated by the temperature feedback only without exceeding the failure temperature of the TRISO particles. Such a design represent a good compromise between breeding and (passive) safety, but it does require an increase of the pebble handling rate of the fuel handling system, as compared to the HTR-PM. It also requires a significant increase of the reprocessing rate, compared to the other options, which may present an economic challenge.

For the third configuration (Table 9 - case IV) with 10 w\% U-233 per driver pebble, the use of a larger driver zone $(110 \mathrm{~cm})$ leads to a longer driver pebble residence time and thus a lower average U-233 weight fraction in the driver zone, as compared to the second case. Therefore, the maximum reactivity insertion due to water ingress is reduced to $+544 \mathrm{pcm}$. This reactor can be considered the best choice among the cores considered in terms of passive safety while still providing a high-conversion reactor $(C R=0.9660)$ within practical constraints, such as the pebble handling speed.

\subsection{Engineering issues}

Fig. 15 gives a more detailed look into the spatial temperature distribution and its influence on the mass flow for case II of Table 9. This case is taken out as a reference, but the analysis and issues that will be addressed in the following occur in a similar way, perhaps to a somewhat weaker or stronger extent, in the other configurations.

During normal operation, the highest temperatures occur in the central region near the bottom of the core, as cold helium enters the core at the top and hot helium leaves at the bottom. The coolant hardly heats up in the breeder zone, where the power density is low, and significantly in the driver zone, where most of the power is produced. This clearly shows the need to separate the driver zone hot helium outflow from the relatively cold helium flowing out of the breeder zone. Fig. 15 also shows that, as expected, the maximum fuel temperature during a DLOFC without scram occurs close to the position where the maximum power density occurs during normal operation. The power density drops rapidly near and inside the breeder channel, which probably makes the reactivity worth of control rods in the side reflector insufficient. The reactivity control system for the two-zone passively safe thorium breeder PBR is investigated in another work by the authors (Wols et al., 2014c).

The total helium mass flow rate $(480.2 \mathrm{~kg} / \mathrm{s}$, including a total bypass flow rate of $26.3 \mathrm{~kg} / \mathrm{s}$ through the side reflector) is also very high for a $100 \mathrm{MWth}$ core, as compared to $96 \mathrm{~kg} / \mathrm{s}$ in the $250 \mathrm{MWth}$ HTR-PM. This is because only a small fraction of the helium coolant flows through the driver zone, which only constitutes $11.11 \%$ of the total core volume. Especially for cores with a large breeder zone, a large mass flow rate is required to ensure the (average) driver zone outlet temperature is $750^{\circ} \mathrm{C}$. This may significantly reduce the efficiency of the reactor due to the large pumping power requirement.

Furthermore, as discussed in Section 3.2, the helium expands much more in the hot driver zone than in the breeder zone, so there is a net deflection of the mass flow from the central driver zone into the breeder zone. This is clearly shown in the lower right graph of Fig. 15, which shows the evolution of the axial mass flow through the driver zone and the breeder zone as a function of core 

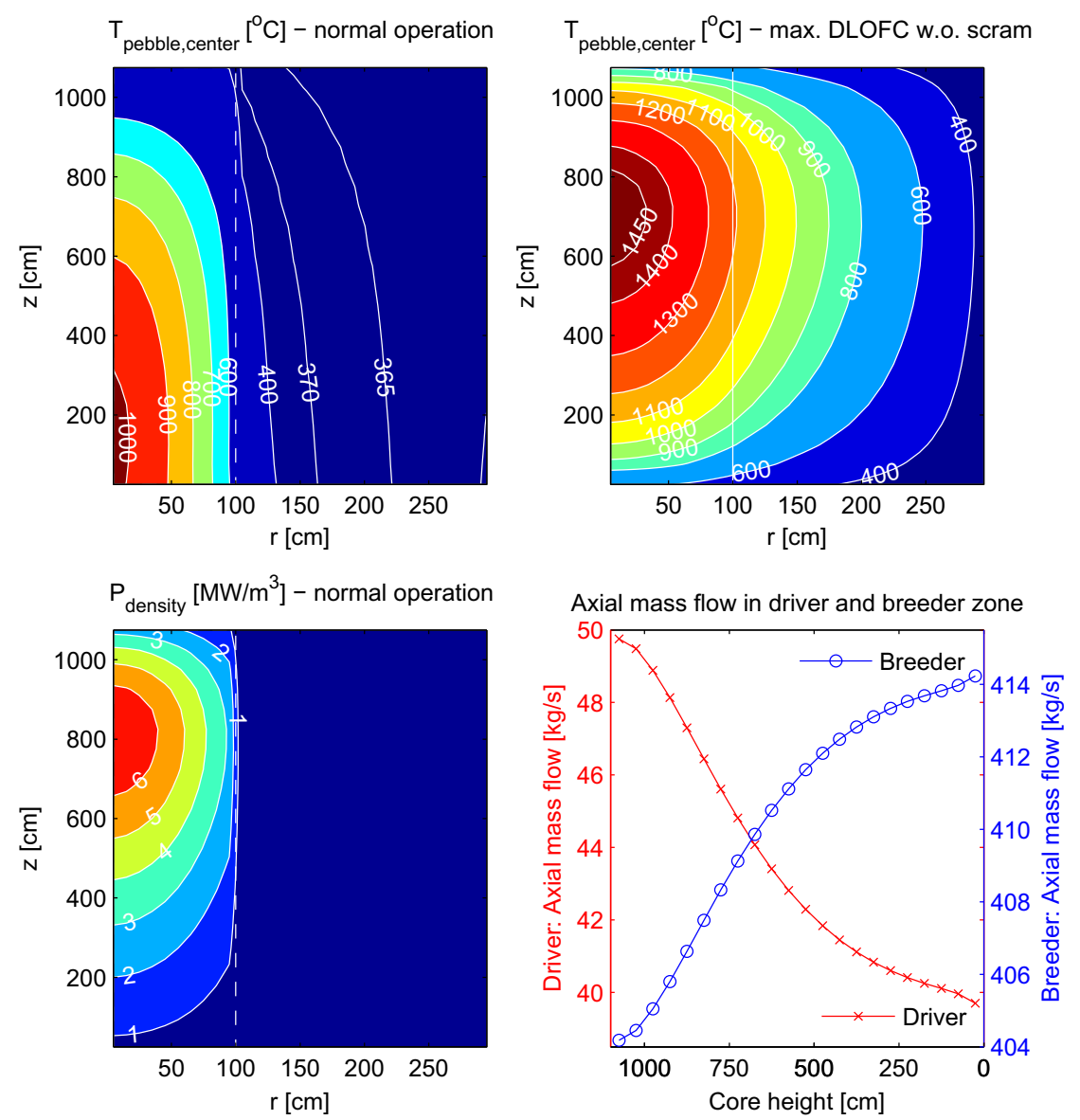

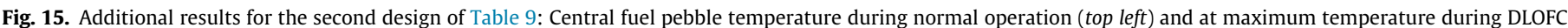

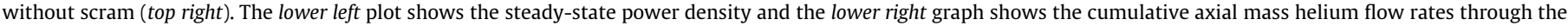
driver zone $(R<100 \mathrm{~cm})$ and through the breeder zone $(R>100 \mathrm{~cm})$ as a function of core height.

height ( $1100 \mathrm{~cm}$ is the top of the core). The axial mass flow rate of the helium through the driver zone drops with $20 \%$ due to this effect. So, besides a factor 9 increase in the mass flow rate due to the large volume of the breeder zone, an additional 25\% increase of the mass flow rate is required for sufficient cooling of the driver zone. On top of this, the average inlet temperature of the helium in the core has increased to $364.5^{\circ} \mathrm{C}$, due to the mixing with the preheated helium exiting the breeder zone. This requires a higher helium mass flow rate to limit the outlet temperature of the driver zone to $750{ }^{\circ} \mathrm{C}$.

One possible solution for these issues, i.e. the large helium mass flow rate and the probably insufficient worth of the control rods, could be provided by using a graphite layer to separate the driver from the breeder zone. This way, the pebble flow speed and helium mass flow rate in the driver and breeder zones can be selected separately, also in practice. This graphite layer could also be used to accommodate control rods and absorber balls. Disadvantages are that this graphite layer may have to be relatively thick to ensure the structural integrity of the core. The influence of such a layer upon the conversion ratio, i.e. increased moderation of neutrons travelling from the driver into the breeder zone and the different geometrical distribution of the core, should also be investigated.

An interesting alternative approach might be the use of a radially cooled pebble bed (Muto and Kato, 2003; Muto et al., 2005; Boer et al., 2010a). First of all, the helium coolant will flow through both the driver and breeder zones, so a lower helium mass flow is required. The pressure drop is much lower, further decreasing power losses to the coolant pump. A radially cooled reactor design requires the use of a central reflector, which is a very suitable location to position control rods close to the driver zone, ensuring sufficient reactivity worth. On the other hand, it is the question whether a radially cooled design can also perform similar in terms of breeding.

For a further improvement of the decay heat removal, allowing for higher operating powers, the use of a liquid salt coolant might also be considered. The use of a liquid salt coolant has previously been investigated for a regular uranium fueled Pebble Bed Reactor (De Zwaan et al., 2007) and liquid salts are also used in the design of the Pebble Bed-Advanced High Temperature Reactor (Fratoni and Greenspan, 2011). Another interesting advantage is that the system can operate at ambient pressure.

A further relevant engineering question is how much time it will take to achieve the equilibrium core and what start-up strategy should be followed during the running-in phase.

\subsection{Multiple radial burnup zones}

The results presented in this work should be interpreted with the limitations and assumptions of the present code scheme in mind. Especially, the use of a single radial burnup zone for driver and breeder, and subsequent use of uniform pebble flow speeds in driver and breeder zone, may influence the conversion ratio obtained by the depletion calculations. Extensive studies with more radially detailed models would be desirable for future validation and optimization, but these were considered beyond the scope of the present work. Using multiple radial depletion zones and a radial velocity profile, adds many degrees of freedom to the core design, because of the large variety in pebble recycling options. 
One could always recirculate pebbles within the same radial burnup zone or they can be randomly reinserted. Pebble recirculation can also be done in many structured ways, e.g. making a first pass through the inner zone and moving outward in the next pass, without violating pebble flow conservation constraints. This fuel management scheme can be optimized with regard to safety, i.e. reduce the maximum power density, conversion ratio or fuel pebble handling speed, by increasing the driver pebble residence time. The conceptual core designs presented in the present work are a good starting point for such more detailed future studies. However, this is only the case if the use of additional radial zones has a limited influence upon the conversion ratio. For this reason, some additional calculations were performed to investigate the effect of adding more radial depletion zones.

Two additional simulations were performed for the passively safe breeder configuration (case II of Table 9) using 8 radial burnup zones ( 3 driver zones with a $40 \mathrm{~cm}, 30 \mathrm{~cm}$ and $30 \mathrm{~cm}$ thickness respectively and 5 breeder zones, all with a thickness of $40 \mathrm{~cm}$ ) within an extended version of the equilibrium core calculation model. In the first additional simulation, the discharged pebbles are reinserted within the same radial zone, while in the second simulation this was done randomly for both driver and breeder zone. The random reinsertion was simulated by equalizing the mass and concentrations of all nuclides according to their average mass fractions in the pebbles flowing out of the different radial burnup zones. The weight fraction of isotope $x, \epsilon_{x, \text { insert }}^{\text {pas }}$, in the randomly reinserted pebbles, was calculated according to

$\epsilon_{x, \text { insert }}^{\text {pass }+1}=\frac{\sum_{j=1}^{\text {zones }} \epsilon_{x, \text { out }}^{j, \text { pass }} \dot{m}_{j}}{\sum_{j=1}^{\text {zones }} \dot{m}_{j}}$,

where the index $j$ sums over the number of radial zones of the driver zone or the breeder zone, and $\dot{m}_{j}$ is the mass flow rate of heavy metal through radial burnup zone $j$.

A constant driver and breeder pebble residence time was assumed over the whole driver or breeder zone, in consistence with the results previously shown in this work. Secondly, a velocity profile with faster speeds in the inner part of driver and breeder zone is expected to weaken the effect of using multiple radial zones, as pebbles reside shorter in the high flux regions leading to a more even distribution of fuel depletion in the driver zone and thorium conversion in the breeder zone. The results are shown in Table 10.

Clearly, the simulation with recirculation of pebbles in the same zone, shows the most extreme effect of adding multiple zones. The $\mathrm{U}-233$ concentration builds up more rapidly in the most inner breeder burnup zone of the multi-zone model. As a consequence, the $k_{\text {eff }}$ would increase with the original 80.4 days residence time, requiring an increase of the driver pebble residence time to obtain a critical core configuration. With random pebble reinsertion this effect is somewhat weaker, explaining the more limited increase in driver pebble residence time. However, the change of the conversion ratio is somewhat larger (and negative) for the case of random re-insertion, but the impact is still very limited. If pebbles would make many (random) pebble passages, results should

\section{Table 10}

Comparison of conversion ratio, driver pebble residence time and maximum power density for the original scheme with two radial burnup zones and the updated scheme using 8 radial zones with pebbles reinserted in the same zone and with random reinsertion.

\begin{tabular}{llll}
\hline & 2 zones & 8 z. same & 8 z. random \\
\hline Conversion ratio & 1.0036 & 1.0040 & 1.0024 \\
$T_{\text {restort }}^{\text {driver }}[\mathrm{d}]$ & 80.4 & 138.9 & 112.7 \\
$P_{\text {density }}^{\max }\left[\mathrm{MW} / \mathrm{m}^{3}\right]$ & 6.9 & 5.3 & 5.7 \\
\hline
\end{tabular}

Table 11

Comparison of conversion ratio, driver pebble residence time and maximum power density for the original scheme with two radial burnup zones and the updated scheme using 8 radial zones with random pebble reinsertion for three cases.

\begin{tabular}{llll}
\hline & CR & $T_{\text {res,tot }}^{\text {driver }}[\mathrm{d}]$ & $P_{\text {dens }}^{\max }\left[\mathrm{MW} / \mathrm{m}^{3}\right]$ \\
\hline Table 9 C. II (2 z) & 1.0036 & 80.4 & 6.9 \\
Table 9 C. II (8 z) & 1.0024 & 112.7 & 5.7 \\
Table 9 C. IV (2 z) & 0.9660 & 306.2 & 6.3 \\
Table 9 C. IV (8 z) & 0.9670 & 332.3 & 5.5 \\
Table 8 C. III (2 z) & 1.0135 & 170.6 & 10.1 \\
Table 8 C. III (8 z) & 1.0027 & 207.4 & 8.5 \\
\hline
\end{tabular}

become very close to the original model with one radial burnup zone for driver and breeder zone.

The most important observation is that the conversion ratio changes only very little after adjusting the driver pebble residence time, while the fuel pebble handling speed and the maximum power density decrease with the multi-zone depletion model. For this specific case, the use of one radial burnup zone for driver and breeder has produced an accurate estimate of the conversion ratio, while the results are conservative in terms of safety, i.e. maximum power density, and practical constraints, i.e. fuel pebble handling speed.

Also for other configurations, it can be expected that using multiple radial burnup zones leads to an increase of U-233 concentrations in the inner part of the breeder zone with similar consequences as for the specific case demonstrated, being an increase of the breeder pebble residence time and a decrease of the maximum power density. However, the change of the conversion ratio is expected to be limited. In order to support this, two additional calculations (with random reinsertion) were performed for case III of Table 8 and case IV of Table 9. These designs have been presented as optimal in terms of either a high conversion ratio or passive safety within practical constraints. The results are shown in Table 11.

For the first additional case considered, i.e. case IV of Table 9, the effect of adding more radial burnup zones is similar as for the first configuration. So, there is an increase of the driver pebble residence time and a decrease of the maximum power density, while the conversion ratio is hardly affected. For the second additional case, i.e. case III of Table 8 , the driver pebble residence time also increases and the power peak decreases. Although the conversion ratio drops by more than $1 \%$, the reactor is still a breeder.

This analysis shows that the conversion ratios obtained with a single radial burnup zone for driver and breeder provide a reasonable estimate of the breeding potential of the different core configurations, while the results are conservative in terms of safety and fuel pebble handling speed.

\section{Conclusions and recommendations}

The present work has studied the breeding potential and passive safety of a two-zone thorium Pebble Bed Reactor. With reprocessing, it is possible to achieve breeding in a thorium Pebble Bed Reactor. With an $18 \mathrm{w} \% \mathrm{U}-233$ content of the driver fuel, breeding can already be achieved for a $220 \mathrm{~cm}$ core radius within a practical operating regime, in terms of power ( $\geqslant 100 \mathrm{MWth})$, breeder pebble residence time ( $\leqslant 1000$ days) and fuel pebble handling time $(\geqslant 14.5 \mathrm{~s}$ per pebble). On the downside, such a design is not passively safe due to the strongly undermoderated state of the driver zone, which results in a weak temperature feedback and a possibly strong reactivity increase in case of water ingress.

An alternative design uses a lower U-233 content in the fresh driver pebbles $(10 \mathrm{w} \%)$ and has a $250 \mathrm{~cm}$ core radius and a $110 \mathrm{~cm}$ driver zone. This configuration presents a passively safe 
thorium PBR and also operates within the same practical operating regime. The maximum fuel temperature reaches $1430{ }^{\circ} \mathrm{C}$ during a DLOFC without scram, which is sufficiently below the TRISO failure temperature. The core is also quite insensitive to a reactivity increase due to water ingress $(+544 \mathrm{pcm})$. Disadvantage is that this design is not a breeder reactor, but it is still a high conversion reactor $(\mathrm{CR}=0.9660)$.

If the fuel pebble handling speed can be increased by a factor two, as compared to the regular HTR-PM, a compromise combining breeding $(C R=1.0036)$ and passive safety $\left(T_{\text {scram }}^{\max \text { DLOFC }}=1481^{\circ} \mathrm{C}\right.$; $\left.\Delta \rho_{\text {water }}^{\max }=1497 \mathrm{pcm}\right)$ can be achieved for a $300 \mathrm{~cm}$ core and $100 \mathrm{~cm}$ driver zone radius. Obviously, in terms of safety and sustainability this represents the most attractive option.

Besides the engineering issues addressed in the previous subsection, (the costs of) the fuel reprocessing (Lung, 1997) may also provide a challenge for practical application of these designs. Especially for the last configuration the required reprocessing rate is very high. Fortunately, Fütterer et al. (2010) recently reported relevant progress on the fragmentation of coated particle fuels, by using high voltage discharges inside a water vessel.

Furthermore, the accuracy of the calculation schemes can still be improved further by the use of newer neutron cross section libraries (ENDF/B-VII), but a broad group library structure like the 44-group ENDF/B-V library is not available (yet), while the use of 238-group libraries would significantly increase computation times. Secondly, the use of a specific decay heat profile for U-233 (instead of U-235) and a more accurate spatial decay heat profile, i.e. depending on the spatial burnup distribution, will influence the maximum temperature during a DLOFC. However, it should also be noted that the influence of these modelling refinements upon the conversion ratio or passive safety does not necessarily have to be negative.

Finally, results in Section 5.5 indicate that more radially detailed models can be used to minimize the maximum power density or the fuel pebble handling speed while preserving a similar conversion ratio. More realistic non-uniform radial pebble flow velocity profiles, under the influence of the conus region and defueling chute(s), can also be included in such more detailed studies.

\section{Appendix A. Numerical calculation of Xenon concentration over time}

The Iodine-135 and Xenon-135 concentrations, denoted by I and $\mathrm{X}$, evolve over time according to (Duderstadt and Hamilton, 1976, p. 569):

$$
\begin{aligned}
& \frac{\partial I}{\partial t}=\int_{0}^{\infty} \gamma_{I} \Sigma_{f} \phi(r, E, t) d E-\lambda_{I} I(r, t) \\
& \frac{\partial X}{\partial t}=\int_{0}^{\infty} \gamma_{X} \Sigma_{f} \phi(r, E, t) d E+\lambda_{I} I(r, t) \\
& -\lambda_{X} X(r, t)-\int_{0}^{\infty} X(r, t) \sigma_{a}^{X e} \phi(r, E, t) d E
\end{aligned}
$$

Where $\gamma_{I}$ and $\gamma_{X}$ are the fission product yields, and $\lambda_{I}$ and $\lambda_{X}$ the decay constants of I-135 and Xe-135. $\Sigma_{f}$ represent the fission cross section, $\phi(r, E, t)$ the scalar neutron flux and $\sigma_{a}^{X e}$ is the microscopic Xe-135 absorption cross section. The time-evolution of I-135 and Xe-135 can be described numerically using an implicit Euler scheme:

$$
\begin{aligned}
P^{j+1} & =\frac{I^{j}+\sum_{g} \gamma_{I} \Sigma_{f, g}^{h e t} \phi_{g}^{j+1} \Delta t}{1+\lambda_{I} \Delta t} \\
X^{j+1} & =\frac{X^{j}+\sum_{g} \gamma_{X} \Sigma_{f, g}^{h e t} \phi_{g}^{j+1} \Delta t+\lambda_{I} P^{j+1} \Delta t}{1+\lambda_{X} \Delta t+\sum_{g} \sigma_{a, g}^{X e} \phi_{g}^{j+1} \Delta t}
\end{aligned}
$$

With $\mathrm{j}$ being the time step number, $\mathrm{g}$ the neutron group number, $\sigma_{a, g}^{X e}$ the microscopic Xe-135 absorption cross section and $\Sigma_{f, g}^{\text {het }}$ the fission cross section in the fuel kernel (so not homogenized with the moderator and helium). During a fully coupled run of the coupled code scheme $\phi^{j+1}$ is obtained using the DALTON diffusion code, while during the loosely coupled run a flux value of zero is applied. Using the ICE module of SCALE6 (ORNL, 2009) a new xenonadjusted cross section library is created. For each zone, this effectively results in

$$
\Sigma^{*}=\Sigma+\left(X^{j+1}-X(0)\right) \frac{V_{\text {fuel }}}{V_{p e b+H e}} \sigma_{X}
$$

Here $\Sigma$ represents the cross section in the temperature interpolated library for all relevant processes, i.e. capture, elastic and inelastic scattering, fission etc. This cross section $\Sigma$ was obtained for the different core zones using the steady-state xenon concentration, and $X(0)$ is the xenon concentration of the steady state configuration. The volume ratio between fuel and homogenized pebble material, $V_{f u e l} / V_{p e b+H e}$, is included in the equation since the microscopic xenon cross section $\sigma_{X}$ has to be smeared over the whole pebble (plus coolant) as $\Sigma$, used by the neutron diffusion solver DALTON, is a homogenized set of cross sections.

\section{References}

American Nuclear Society, 1993. ANSI/ANS-5.1-1993: Decay Heat Power in Light Water Reactors.

Boer, B., Lathouwers, D., Kloosterman, J.L., van der Hagen, T.H.J.J., van Dam, H., 2010a. Optimization of a radially cooled pebble bed reactor. Nucl. Eng. Design 240, 2384-2391.

Boer, B., Lathouwers, D., Kloosterman, J.L., van der Hagen, T.H.J.J., Strydom, G., 2010b. Validation of the DALTON-THERMIX code system with transient analyses of the HTR-10 and application to the PBMR. Nucl. Technol. 170, 306321.

De Zwaan, S.J., Boer, B., Lathouwers, D., Kloosterman, J., 2007. Static design of a liquid-salt-cooled pebble bed reactor (LSPBR). Ann. Nucl. Energy 34, 83-92.

Duderstadt, J.J., Hamilton, L.J., 1976. Nuclear Reactor Analysis. John Wiley and Sons Inc.

Fratoni, M., Greenspan, E., 2011. Neutronic feasibility assessment of liquid saltcooled pebble bed reactors. Nucl. Sci. Eng. 168, 1-22.

Fütterer, M.A., von der Weid, F., Kilchmann, P., 2010. A high voltage head-end process for waste minimization and reprocessing of coated particle fuel for high temperature reactors. In: Proceedings of ICAPP'10.

IAEA, 2005. Thorium Fuel Cycle - Potential Benefits and Challenges. Technical Report IAEA-TECDOC-1450, Vienna.

Ilas, G., Hudson, N.H., Rahnema, F., Ougouag, A.M., Gougar, H.G., 2006. On a fewgroup cross-section generation methodology for PBR analysis. Ann. Nucl. Energy 33, 1058-1070.

Kugeler, K., Kugeler, E., Pöppe, N., Alkan, Z., Grätz, W., Energy, Nuclear, 2005. Volume 3B of Landolt-Börnstein - Group VIII: Advanced Materials and Technologies Series. Springer, Berlin Heidelberg, p. 147.

Lung, M., 1997. EUR 17771: A Present Review of the Thorium Nuclear Fuel Cycles (European Commission). Technical Report ISSN 1018-5593.

Lung, M., Gremm, O., 1998. Perspectives of the thorium fuel cycle. Nucl. Eng. Design $180,133-146$.

Melese, G., Katz, R., 1984. Thermal and flow design of helium-cooled reactors. Am. Nucl. Soc..

Muto, Y., Kato, Y., 2003. A new pebble bed core concept with low pressure drop. In: Transactions of the Global 2003 Conference, New Orleans, LA. pp. 1202-1209.

Muto, Y., Kato, Y., Udagawa, R., 2005. Improvement of fuel temperature characteristics in a pebble bed core with horizontal flow by means of fuel zoning. In: Proceedings of ICAPP05, Seoul, Korea.

ORNL, 2009. SCALE: A Modular Code System for Performing Standardized Computer Analyses for Licensing Evaluations, Vols. I-III, Version 6, CCC-750; ORNL/TM2005/39. Radiation Safety Information Computational Center, Oak Ridge National Laboratory.

Schenk, W., Pott, G., Nabielek, H., 1990. Fuel accident performance testing for small HTRs. J. Nucl. Mater. 171, 19-30.

Struth, S., 1995. Thermix-Direkt: Ein Rechenprogramm zur instationSren zweidimensionalen Simulation thermohydraulischer Transienten. FZ Jülich, Germany.

Teuchert, E., 1986. Brennstoffzyklen des Kugelhaufen-Hochtemperaturreaktors in der Computersimulation. Kernforschungsanlage Jülich $\mathrm{GmbH}$

Van Dam, H., 1996. Dynamics of passive reactor shutdown. Prog. Nucl. Energy 30 (3), 255-264.

Wols, F.J., Kloosterman, J.L., Lathouwers, D., 2012. Fuel pebble design studies of a high temperature reactor using thorium. In: High temperature Reactor Conference 2012, Tokyo, Japan. HTR2012-5-002. 
Wols, F.J., Kloosterman, J.L., Lathouwers, D., van der Hagen, T.H.J.J., 2014a. Core design and fuel management studies of a thorium-breeder pebble bed hightemperature reactor. Nucl. Technol. 186, 1-16.

Wols, F.J., Kloosterman, J.L., Lathouwers, D., van der Hagen, T.H.J.J., 2014b. Preliminary safety analysis of a thorium breeder pebble bed reactor. In: PHYSOR-2014 - The Role of Reactor Physics towards a Sustainable Future, Kyoto, Japan. Contribution submitted in Dec 2013.

Wols, F.J., Kloosterman, J.L., Lathouwers, D., van der Hagen, T.H.J.J., 2014c. Reactivity Control System for a 100 MWth Passively Safe Thorium Breeder Pebble Bed Reactor. Submitted to Nuclear Engineering and Design.
Zheng, Y., Shi, L., 2008. Characteristics of the $250 \mathrm{MW}$ pebble-bed modular high temperature gas-cooled reactor in depressurized loss of coolant accidents. In: High temperature Reactor Conference 2008, Washington, DC USA. HTR200858299.

Zheng Y, Shi, L, Dong Y, 2009. Thermohydraulic transient studies of the Chinese 200 MWe HTR-PM for loss of forced cooling accidents. Ann. Nucl. Energy 36 $742-751$

Zheng, Y., Shi, L., Yan, W., 2010. Water-ingress analysis for the 200 MWe pebble-bed modular high temperature gas-cooled reactor. Nucl. Eng. Design 240, 3095 3107. 